JOSÉ MARÍA DUARTE CRUZ ${ }^{*}$

CONACYT - El Colegio de la Frontera Sur (Chiapas, México)

JOSÉ BALTAZAR GARCÍA-HORTA**

Universidad Autónoma de Nuevo León (Monterrey, México)

\title{
Igualdad, Equidad de Género y Feminismo, una mirada histórica a la conquista de los derechos de las mujeres ${ }^{* * *}$
}

\author{
Equity, Gender Equality and Feminism, a historical look \\ at the conquest women's rights
}

Igualdade, Equidade de Gênero e Feminismo, uma visão
histórica da conquista dos direitos das mulheres

* Doctor en filosofía con especialidad en trabajo social y políticas comparadas de bienestar social por la Universidad Autónoma de Nuevo León. Catedrático de CONACYT, Comisionado en El Colegio de la Frontera Sur, Unidad San Cristóbal de las Casas, Chiapas, México. Correo electrónico: duartecruz2911@hotmail.com

** Doctor en filosofía con especialidad en educación por la Universidad de Leeds en Reino Unido. Profesor investigador de la Facultad de Trabajo Social y Desarrollo Humano de la Universidad Autónoma de Nuevo León, Monterrey, México. Correo electrónico: jose.garciaht@uanl.edu.mx

*** Este trabajo es resultado del proyecto de investigación titulado: Sexismo y equidad de género en educación primaria. Lecciones de escuelas públicas en Monterrey y Ciudad de Panamá, desarrollado en el 2013 en el marco del doctorado en filosofía con orientación en trabajo social y políticas comparadas de bienestar social por la Facultad de Trabajo Social y Desarrollo Humano de la Universidad Autónoma de Nuevo León, México. Artículo de investigación recibido el o9/02/2015 y aceptado el 18/01/2016. 


\section{Cómo citar}

DuArte Cruz, J. M. y GarcíA-Horta, J. B. (2016). Igualdad, Equidad de Género y Feminismo, una mirada histórica a la conquista de los derechos de las mujeres. Revista CS, no. 18, pp. 107-158. Cali, Colombia: Facultad de Derecho y Ciencias Sociales, Universidad Icesi.

DOI: http://dx.doi.org/10.18046/recs.i18.1960 


\section{Resumen}

Abstract

Resumo

La Convención sobre la eliminación de todas las formas de discriminación contra la mujer (CETFDCM) define el concepto de igualdad y dice cómo lograrla. Las políticas proponen marcos de referencia para que vivamos de manera igualitaria, pero ¿cómo hacerlo si la misma sociedad es la que enseña a ser desiguales? Este trabajo ofrece un panorama histórico de los avances y retrocesos en materia de equidad de género. Al escudriñar este fenómeno quizás nos acerquemos a conocer una realidad social que impacta a hombres y mujeres de manera distinta. Actualmente se dejan entrever avances en materia de equidad de género, pero a su vez se manifiestan formas inequitativas que siguen privilegiando los roles masculinos sobre los femeninos.

\section{PALABRAS CLAVE:}

Igualdad de género | equidad de género | perspectiva de género | feminismo

The Committee on the Elimination of Discrimination against Women (CEDAW) defines equality and says how to achieve it. The policies propose frameworks to live equally, but: how do you do this if it is society that teaches us to be unequal? This paper provides a historical overview of progress and setbacks on gender equality. By examining this phenomenon perhaps we get to know a social reality that impacts men and women differently. Currently, progress on gender equality can be seen, but in turn, inequitable ways that continue to favor male roles over the female are manifested.

\section{KEYWORDS:}

Gender equality | gender equity | gender perspective | feminism

A Convenção sobre a eliminação de todas as formas de discriminação contra a mulher (CETFDCM) define o conceito de igualdade e diz como alcançá-la. As políticas propõem marcos de referência para que vivamos de maneira igualitária, mas, como fazê-lo se a própria sociedade é a que ensina a ser desiguais? Este trabalho oferece um panorama histórico dos avanços e retrocessos em matéria de equidade de gênero. Ao escudrinhar este fenômeno, 
talvez estejamos chegando mais perto de conhecer uma realidade social que impacta homens e mulheres de maneira diferente. Atualmente se deixam entrever avanços em matéria de equidade de gênero, mas por sua vez se manifestam formas não equitativas que continuam privilegiando os papéis masculinos sobre os femininos.

\section{PALAVRAS CHAVES:}

Igualdade de gênero | equidade de gênero | perspectiva de gênero | feminismo 


\section{Antecedentes históricos sobre los conceptos equidad e inequidad de género y el lugar de la mujer}

En 1968, el profesor e investigador norteamericano Robert Stoller utilizó por primera vez el concepto de género en su libro Sexo y Género - en inglés: Sex and Gender- para oponerlo al sexo (significando este el conjunto de diferencias anatómicas y biológicas entre hombres y mujeres), subrayando de esta manera el carácter socialmente construido de las nociones de masculinidad y feminidad. Cuatro años más tarde, Ann Oakley (1972) popularizó el término con su libro Sexo, Género y Sociedad, que tuvo una enorme divulgación. Algunas feministas americanas se apoderaron pronto de este concepto porque les permitía sobrepasar el determinismo biológico que impedía la liberación de la mujer de la opresión patriarcal.

Lo que determina la identidad y el comportamiento masculino o femenino no es el sexo biológico, sino el hecho de haber vivido desde el nacimiento las experiencias, ritos y costumbres atribuidos a los hombres o las mujeres; además, la asignación y adquisición de una identidad es más importante que la carga genética, hormonal y biológica (Stoller, 1968).

El concepto de género comienza a surgir a mediados de los años setenta, según la OEA, como respuesta a las interrogantes teóricas-metodológicas planteadas por la constatación de evidentes asimetrías y desigualdades existentes entre hombres y mujeres en función de su sexo. En 1974 se firmó en Argelia la Declaración del Establecimiento de un Nuevo Orden Económico Internacional, que pretendió corregir las desigualdades existentes. Este hecho marcó la pauta para la celebración de la primera Conferencia Mundial de la Mujer en México, en 1975, en ella se habló sobre discriminación, salud y desarrollo económico (Chiarotti, 1995).

Este hecho visibilizó por primera vez en todas las esferas, las condiciones de discriminación, opresión, subordinación, segregación y maltrato a que eran sometidas miles de mujeres en el planeta; además de poner en evidencia la necesidad y la exigencia moral y económica de sumar a las mujeres a los procesos de desarrollo y democráticos de los países (Lamas, 2007).

La historia del concepto de género fue inicialmente concebida como una especie de difusión de la historia de las mujeres, permitiendo según Natalie Zemon Davis (1976), redefinir sus objetivos en el sentido de "descubrir las variaciones de los papeles y significados de los roles sexuales en diferentes sociedades y períodos, comprender lo que representaban y cómo funcionaban para mantener el orden social o promover su cambio".

La francesa Simonne de Beauvoir (1949) había ya expresado que "no se nacía mujer, sino que se convertía en ello”. De esta manera advirtió que el sexo está más ligado a la esfera biológica, a aquello que se trae al nacer, y que la noción de género tiene más bien 
un carácter sociocultural, que es construida dentro de la sociedad en particular donde se desenvuelve el individuo, y es aquí donde se vuelve o no efectiva, intentando regular el orden de las cosas y el comportamiento de las personas (Álvarez, 2007).

Fue Joan Scott (1986), en el artículo "El género, una categoría útil para el análisis histórico", quien teorizó este concepto, haciendo de él algo más que una moda académica y editorial, es decir, estableció una categoría de análisis histórico. Para Scott, el género no es solo la construcción social de la diferencia sexual, sino también una forma de significar las relaciones de poder. Según Seabra de Almeida (2009), la elaboración de este doble concepto permitió, por un lado, mirar las relaciones sociales opresivas de otra manera, no colocando a las mujeres en la posición de víctimas y a los hombres en la de opresores, sino buscando para cada contexto cronológico, geográfico y cultural las posiciones relativas de cada grupo en la intersección del género con la clase, la raza, etc.; además, hizo posible no solo seguir estudiando a las mujeres como seres sexuados, condicionados por las expectativas que la sociedad tiene en relación a lo que es apropiado a su sexo, sino también empezar a hacer lo mismo en relación a los hombres (Seabra, 2009).

Las ideas y simbolismos que actualmente interpretamos como equidad de género se han ido transformando y han evolucionado a lo largo de la historia de la humanidad. A través de una revisión histórica se plantea el surgimiento y la apropiación de los conceptos de equidad e inequidad de género, así como los roles de la mujer, el nacimiento del patriarcado, y en él las relaciones de poder, la construcción de los roles de género y las manifestaciones de igualdad-desigualdad en las organizaciones sociales; también se rescatan reflexiones y documentos que evidencian el papel que la educación ha desempeñado en el desarrollo de una formación no sexista.

Se consideran valiosas las aportaciones que escritores/as, filósofos/as, políticos/as, investigadores/as, científicos/as y diversas personalidades hicieron en su momento, ya que enmarcaron lo que hoy en día se conoce como equidad e inequidad de género; además, sus ideas sirvieron para generar un espacio de reflexión y establecer posteriormente las convenciones, tratados y legislaciones actuales en esta materia.

Para comprender el rol de estos conceptos en diversas sociedades en el mundo es preciso conocer los puntos de vista de quienes protagonizaron dichos acontecimientos. La presente revisión se estructura en cuatro grandes bloques o períodos históricos: Primeras sociedades prehistóricas, Edad Media (siglos V al XV), Edad Moderna (siglos XV al XVIII), y Edad Contemporánea (finales del siglo XVIII hasta el presente); este último período se describe detalladamente, pues en su curso se marcaron hitos importantes en materia de equidad e inequidad de género. 


\section{La equidad de género en las primeras sociedades prehistóricas}

El estudio de la historia humana reafirma que somos seres sociales y que la sociedad decide sus formas propias de organización a través de las tradiciones culturales; de allí que existan diferencias en las teorías que intentan explicar estas formas de estructuración social y familiar de los primeros seres humanos.

Desde tiempos prehistóricos se identifican diferencias entre los hombres y las mujeres, no solo físicas sino de género, que determinaban la supremacía y el poder que ejercía un sexo sobre el otro. Para algunos investigadores y pensadores (Engels y Marx, 1846; Fontenla, 2008; Martínez, 2003; Sánchez, 2007; Soler, 2006), en tiempos prehistóricos a las mujeres se les vinculó con el espacio del hábitat; consideradas como acompañantes y objetos sexuales, cuyo papel principal era la reproducción. El status que se ofrecía a los hombres no era el mismo que a las mujeres, a ellos se les otorgaba el derecho de mandar, basándose en una supuesta superioridad biológica y social. En este sentido, Frappant (2008) sostiene que la organización social de los primeros homínidos estaba formada por un macho dominante que gobernaba el destino de los otros machos del clan y la cópula con hembras era decisión suya.

Investigaciones realizadas por el etno-arqueólogo Jean-Michel Chazine (2009), en el Centro de Investigación y de Documentación en Oceanía, sobre las manos negativas pintadas en cientos de cuevas en todo el mundo, señalan que los hombres y las mujeres que vivían en las cavernas en la prehistoria dejaban en lugares diferentes las huellas de sus manos, sin mezclarlas en las paredes de las grutas (Carletti, 2006). Estos descubrimientos fueron realizados utilizando un programa informático creado para estudiar la cueva de Gua Masri II en Indonesia. Según este científico:

Los descubrimientos de las pinturas de manos han tomado gran importancia, ya que se ha puesto en evidencia que los rituales de los hombres en las sociedades primitivas no se mezclaban con los de las mujeres; aunque no se han establecido las causas de esta separación, sí se puede afirmar que la presencia femenina tenía un papel mágico y chamánico en estas organizaciones sociales (Chazine, 2009: 46).

La arqueóloga española Margarita Sánchez Romero (2007), ha realizado investigaciones sobre lo que denomina "identidad de género en la prehistoria" que evidencian el importante papel femenino en ese período; para ella, las mujeres han estado históricamente vinculadas a las llamadas actividades de mantenimiento, aquellas relacionadas con la preparación del alimento, raspar la piel de animales, elaborar prendas de vestir, la preservación de adecuadas condiciones de higiene y salud, el cuidado del fuego, además del cuidado del resto de los miembros del grupo y de la socialización de los individuos infantiles. Sin embargo, el problema es que las actividades domésticas se han estimado tradicionalmente como fáciles y sin necesidad de mucho esfuerzo, ya 
que requieren de la utilización de tecnologías básicas y de poca experiencia para su desarrollo (Sánchez, 2007).

En todas las sociedades ha existido una división del trabajo por sexos (Engels y Marx, 1846). Esta separación no implica que un grupo realice tareas menos importantes que el otro, sino que es una estrategia social para la explotación de los recursos. Algunas teorías apuntan a que en este período histórico fue fundamental la vinculación de las mujeres con el trabajo de cuidado de los hijos/as, ya que estos requieren una atención constante durante los primeros años de vida. En las sociedades prehistóricas la lactancia de los infantes era un recurso fundamental, esto vinculó a las mujeres a las actividades de mantenimiento y al espacio doméstico, sin que significara necesariamente desigualdad o subordinación. Sobre este aspecto Sánchez Romero (2007) indica:

Las mujeres realizaban labores esenciales en el mantenimiento de sus sociedades y al igual que los hombres, intervenían en todas las actividades propias de un grupo, desde las religiosas, hasta las de provisión de alimentos. También las mujeres se dedicaban a la caza, a pescar, a cultivar el campo, a recolectar, a atender a los niños y a lo que hiciera falta (Sánchez, 2007:1).

El papel activo que desempeñó la mujer en todos los ámbitos de la vida, no sólo en lo doméstico, nos hace reflexionar sobre la veracidad de ideas prevalecientes acerca de que solo los hombres se dedicaban a la caza y a otras actividades que requerían de fuerza mayor (Martínez, 2003). Desde el siglo XIX, las investigaciones sobre la prehistoria desarrolladas en Europa han proporcionado un conocimiento exhaustivo de los modos de vida de las sociedades del pasado. Según la arqueóloga Begoña Soler (2006), es fácil comprobar cómo la presencia de la mujer en la mayor parte de los textos y en las imágenes de exposiciones divulgativas es casi nula: por lo general aparece el hombre prehistórico, el neutro masculino, como protagonista. En este sentido, Soler y Alcántara (2006), sostienen que:

(...) los hombres y mujeres de nuestro pasado más lejano formaron grupos de personas que se unieron para obtener mejor calidad de vida, que compartieron esfuerzos y recursos para sobrevivir. Mujeres, hombres, jóvenes, mayores, niños y niñas dejaron el testimonio de su existencia en el suelo en que vivieron (2006: 8).

La reflexión sobre la importancia de las diferentes actividades para sobrevivir y el papel que desempeñaron mujeres y hombres en el paleolítico, el neolítico y la edad de bronce, se conoce por los hallazgos de diversos objetos encontrados en cavernas y sitios de exploración arqueológica, así como el análisis del arte rupestre, la interpretación de los restos humanos localizados en las excavaciones y los análisis de las sociedades prehistóricas a través de la investigación antropológica. 
Para la directora del Museo de Prehistoria en Valencia en España, Helena Bonet (2006), gran parte del análisis de estos hallazgos se ha reconfigurado a través de lo que en la actualidad se conoce como arqueología de género, que no es más que una disciplina surgida al calor de los movimientos feministas de los años sesenta del pasado siglo. La arqueología del género persigue resaltar, a través de publicaciones sobre la cultura prehistórica basadas en el registro arqueológico, la importancia que tuvo la mujer tanto en la vida privada como en la vida pública.

El patriarcado (palabra de origen griego que quiere decir mandar, consiste en la manifestación e institucionalización del dominio masculino sobre las mujeres, los niños/as yla ampliación de este dominio a la sociedad en general) y la subsiguiente construcción de la sociedad patriarcal, se remontan a la antigüedad, cuando el ser humano se convirtió en sedentario y surgió la agricultura. Las familias empiezan a acumular bienes, las actividades de la vida cotidiana se dividen y las normas implantadas permiten solo a los hombres el desarrollo de actividades productivas, y a las mujeres de actividades domésticas (Fontenla, 2008). Esta clara división sexual del trabajo trajo consigo la necesidad de contar con más miembros en las familias para acrecentar los bienes.

La diferencia de quienes deben salir del hogar a buscar el sustento y quienes deben quedarse cuidando los hijos/as, establece los primeros indicios de la creación de sistemas de organización social y política; es decir, lo que conocemos como mundo público y privado. Desde tiempos antiguos muchas sociedades implantaron una dominación física, sexual y social que certificaba el control de la mujer por parte de los hombres. Se empieza a interponer un principio dogmático que suponía la debilidad física e intrínseca de las mujeres y del correspondiente papel protector y proveedor de los hombres, quienes poseen el atributo natural del poder, la fuerza y la agresividad (Pintos, 2007).

En el patriarcado no todas las relaciones eran familiares, esto se deja entrever siglos más tarde con el surgimiento de una nueva clase social, la burguesía, implantada a través del poder de unos sobre otros. Este nuevo fundamento fue el pacto o acuerdo social, mediante el cual se organizó el patriarcado moderno. Aunque en la constitución de esta nueva jefatura, los hombres continuaban manteniendo el poder; ya no solo hacia las mujeres, sino hacia sus semejantes.

La subordinación de las mujeres se acrecentó a través del cuerpo normativo conocido como las Leyes de Partidas, redactado en Castilla en el año 1265, durante el reinado de Alfonso X, con el objetivo de conseguir una cierta uniformidad jurídica del reino en aspectos filosóficos, morales y teológicos. Esta obra es considerada uno de los más importantes legados de jurisprudencia, y es el cuerpo de leyes de más amplia y larga vigencia en Iberoamérica, hasta el siglo XIV. Este conjunto de leyes consolidó la familia patriarcal, con la aprobación de la iglesia católica, una de las instituciones de mayor poder de la época. A lo largo del siglo XIX algunas disposiciones inspiradas en estas legislaciones fueron adoptadas por las leyes de los Estados-nación que se constituyeron 
posteriormente. Con la formación de los Estados, el poder del jefe de familia pasa al gobierno, quien promete garantizar a través de las leyes, la sujeción de las mujeres al padre, al marido y a los varones en general, impidiendo su constitución como sujetos políticos (Fontenla, 2008).

Durante este período se pueden identificar algunos aspectos de importancia, como la clara identificación que se hiciera de los roles y funciones que desempeñaban hombres y mujeres. Desde entonces ellas asumen "actividades de mantenimiento en el espacio privado", mientras que ellos lideran los espacios públicos ejerciendo poder y dominio. Los sistemas de organización social refuerzan estas funciones, se comienza a establecer no solo a las mujeres como "subordinadas", sino a quienes eran considerados como inferiores en el ámbito social y político.

\section{Los roles de género de las mujeres en la Edad Media}

Durante el período conocido como Edad Media (siglos V a XV) la figura femenina estaba condicionada según el lugar que ocupara en una sociedad estamental. Según Patt Knapp y Mónika Von Zell (2007), las mujeres contribuyeron significativamente a la economía medieval. Aunque muchas fueron ignoradas, ya que ni la literatura religiosa ni la romántica ofrecen informaciones precisas sobre las actividades de las mujeres en esta época, algunas cartas, testamentos, documentos comerciales y legales, informaciones en conventos y censos, registran manuscritos que completan el concepto del mundo de las mujeres medievales y sus roles de género.

La iglesia jugó un papel clave mediante la construcción de dos figuras fuertes para identificar a las mujeres: Eva, creada a partir de la costilla de Adán, quien provocara la expulsión de ambos del paraíso; y María, quien representa la virginidad, la castidad y la abnegación como esposa y madre. Se concibe entonces un conjunto de características propias de las mujeres: casta, prudente, trabajadora, honrada, callada, obediente, hermosa y sorprendentemente, culta. Así lo revelan las pinturas y esculturas romanas, mujeres con vientres abultados y senos grandes que las ligan a la fertilidad. A los hombres de esta época les gustaban las mujeres de piel clara, que no se han ennegrecido trabajando al sol, de cabellos rubios y rizados, limpios, cuidados y olorosos.

En la Edad Media, solo la mujer noble podía gozar de ciertos privilegios: se encargaba del cuidado y la educación de los hijos/as, de la organización de los empleados de la casa y de la economía; ocupaban un lugar importante durante la ausencia del esposo, común en épocas de guerras y cruzadas. Frecuentemente eran utilizadas como moneda de cambio de las uniones matrimoniales que servían para sellar pactos estratégicos o políticos. Eran también transmisoras de la dote, aunque no disponían de ella ni casadas ni viudas.

En 1412 nace en la ciudad de Domrémy, Francia, la santa y heroína Juana de Arco. Hija de campesinos acomodados, fue una joven líder en una época de conflictos 
acaecidos en la "Guerra de los Cien Años". A los trece años confesó haber visto a San Miguel, a Santa Catalina y a Santa Margarita, cuyas palabras la exhortaban a ser sirviente y devota de Dios. En 1428, a los 17 años, encabezó el ejército real francés, y convenció al rey Carlos VII de expulsar a los ingleses de Francia. Luego fue capturada, juzgada y condenada por brujería y hechicería: un tribunal eclesiástico argumentó que las voces que le hablaban procedían del diablo, y fue condenada a cadena perpetua. Posteriormente reafirmó el origen divino de las voces que escuchaba, por lo que fue quemada viva el 30 de mayo de 1431, tenía 19 años. En 1909 fue Beatificada por Pio X y canonizada por Benedicto XV en 1920.

Dentro de este período las mujeres campesinas se encontraban en las peores condiciones sociales. Encargadas de todas las tareas domésticas y de la educación de los hijos/as, así como del ganado, el huerto y en ocasiones de la tierra de cultivo. Cuando era soltera o viuda, abandonaba a menudo el hogar para realizar trabajos de jornalera o doméstica. Las mujeres que se dedicaban a vivir como monjas gozaban de cierta "libertad" dentro de los conventos, muchas de ellas tenían acceso a libros prohibidos para el común. Ayudaban a los pobres, enfermos y huérfanos.

En esta época surgieron las "brujas”. Era apreciación de la iglesia la inclusión de cualquier mujer en este grupo: sabían de anatomía, botánica, sexualidad, amor y reproducción, por lo que fueron mandadas a la hoguera. Norma Blazquez Graff, filósofa de la UNAM, dice en su libro El retorno de las brujas (2011) que no eran malas y feas, como las ha descrito la literatura universal, sino mujeres generadoras de un conocimiento específico. En el medievo predominaba un modelo social masculino, y el saber de las brujas fue considerado amenazante, por lo que fue perseguido y destruido junto con ellas en las hogueras:

Las brujas fueron mujeres con conocimientos específicos en alquimia, con lo que elaboraban recetas de perfumería y cosmética. Desarrollaron técnicas de destilación, extracción y sublimación. No eran personas feas ni malas, más bien fueron estereotipadas (Blazquez, 2008).

Las brujas eran parteras, alquimistas, perfumistas, nodrizas o cocineras; tenían conocimientos en diversos campos como la anatomía, la botánica, la sexualidad, etc. Prestaban un importante servicio a la comunidad, conocían mucho de plantas, animales y minerales, y creaban recetas para curar; todo esto fue interpretado por los grupos dominantes del medievo como un poder del Diablo. Por sus conocimientos eran perseguidas y condenadas a la muerte (Blazquez, 2011).

Las elites eclesiásticas, políticas y económicas que se consolidaban en la época medieval, comenzaron a desarrollar un modelo social muy masculino y consideraban que el saber que las mujeres tenían, especialmente en sexualidad y reproducción, representaba una amenaza. Las brujas comenzaron a almacenar conocimiento muy importante sobre el control de la reproducción y sabían preparar diversos abortivos. 
Este conocimiento implicaba la posibilidad de ejercer una sexualidad más libre, lo cual ponía en riesgo la hegemonía masculina y, por ello, los hombres expropiaron su conocimiento y las aniquilaron en las hogueras. Asimismo, la mayoría de estas mujeres vivían solas, en casas en el bosque, independientes, generaban sus propios ingresos; todo esto provocaba mucha desconfianza (Blazquez, 2011).

A finales de la Edad Media se presentó una etapa de crisis en algunos países de Europa y del Mediterráneo por razones centradas en acontecimientos sociales, políticos e ideológicos que, acompañados de cambios climáticos y ambientales, hicieron decrecer la economía y la actividad agrícola; al tiempo que hambrunas y epidemias redujeron la población europea en no menos de un tercio. Se cree que estas situaciones promovieron una crisis general e impulsaron, por un lado, la transición del feudalismo al capitalismo, y por otro dieron nuevo vigor cultural al Renacimiento y a la expansión europea, marcada por los descubrimientos y las conquistas.

En este panorama aparecieron las publicaciones de Cristina De Pizan (1364-1430), poetisa y humanista francesa que evidenció en prosa las calumnias que soportaban las mujeres de su época, así como las hazañas que afrontaban para sobrevivir. Su obra más revolucionaria La ciudad de las damas (1405), es un texto que recurre a tres virtudes: la razón, el derecho y la justicia, para plantear la igualdad como principio humano (Aguirre, 2005).

En su obra, De Pizan deseaba rehabilitar a las mujeres construyendo una ciudad cuyos cimientos, piedras y acabados fuesen ejemplo de las propias mujeres, según ella: virtuosas, guerreras, profetas, amantes, esposas, castas y santas. Por medio de sus escritos, reveló cómo ellas podían aspirar a una mejor vida junto a los hombres, y romper los tabúes del cortejo, el matrimonio y la vida en sociedad (González, 2005). Se considera a esta escritora como la primera feminista de la historia; además, como la primera escritora profesional francesa y una de las más antiguas precursoras del movimiento de las mujeres. Sus obras cuestionaban con atrevida audacia el canon patriarcal predominante, así como a los intelectuales de la época, que catalogó de injustos (Vásquez, 2004).

Para la mayoría de las mujeres en el Renacimiento (siglos XV y XVI), la maternidad era su profesión y su identidad. Sus vidas adultas (desde los 25 años en casi todos los grupos sociales y desde la adolescencia entre las familias más ricas) eran un ciclo continuo de embarazo y crianza. Las mujeres estaban forzadas a ser fértiles, las pobres daban a luz cada 24030 meses. Tener hijos/as constituía una carga y un privilegio de las mujeres.

En lugares como Italia y Francia la mujer que paría era festejada y mimada, era un auténtico honor estar embarazada. El parto era un momento temible, fruto del castigo de Eva por su falsedad en el Paraíso. Las madres que sobrevivían se enfrentaban a menudo a la muerte de la criatura que habían traído al mundo con tanto sufrimiento. Los esposos reprochaban a las mujeres que dieran pecho a su vista; y las mujeres ricas de esta época frecuentemente evitaban amamantar a sus hijos/as, que eran amamantados por mujeres pobres, en estas familias era común tener sus 
propias amas de cría. Con más frecuencia, los recién nacidos de las ciudades de Italia, Francia, Alemania e Inglaterra, eran enviados al campo para que los amamantaran las mujeres campesinas.

La situación de las mujeres plebeyas era abismalmente distinta a la de las mujeres de la nobleza. En la época feudal, la división social entre nobleza y plebe era radical. Las mujeres plebeyas (como los varones plebeyos) permanecían ajenas a toda clase de educación formal, eran en su totalidad analfabetas, y de sus vidas sólo tenemos atisbos provenientes de registros de juicios por brujería y poca cosa más. En la nobleza, las mujeres recibían prácticamente la misma educación que los hombres. La diferencia estaba en que ellas tenían prohibido enseñar; en este sentido el escritor, filósofo y teólogo Gil de Roma decía en uno de sus escritos:

\begin{abstract}
(...) a causa de su débil nexo con la razón, las mujeres se rinden a las pasiones más fácilmente que los hombres (...) No permito que las mujeres enseñen por cuatro razones: la primera es su falta de inteligencia, que tienen en menor medida que los varones; la segunda es la sujeción a que están sometidas; la tercera es el hecho de que, si ellas predicaran, su apariencia provocaría lujuria; y la cuarta es a causa del recuerdo de la primera mujer, quien... enseñó sólo una vez, y eso bastó para poner el mundo del revés (Gil de Roma en Rehermann, 2012:2).
\end{abstract}

Aunque las mujeres fueran tan cultas como el más educado de los hombres, tenían pocas posibilidades de ejercer públicamente su sabiduría. Hay que ser cuidadosos a la hora de tener o no por válida la imagen y discursos que los clérigos (los pocos que sabían escribir), dan sobre la mujer. A pesar de esta dificultad, hoy en día se conocen a grandes féminas medievales como Leonor de Aquitania, Juana de Arco y Cristina De Pizan.

Es realmente difícil determinar si hubo una evolución o un retroceso en la situación de las mujeres en la Edad Media. Fueron diez siglos en los que la sociedad, la cultura y las costumbres sufrieron muchas variaciones; avanzado el tiempo en la Europa cristiana la Iglesia fue ganando poder, entre otros aspectos en lo referente a la moral y el comportamiento femenino. Este orden se reforzó por un sistema social muy rígido de claras diferencias de clase y del papel de las mujeres.

\title{
Edad moderna (siglos XV al XVIII)
}

En la Edad Moderna se presentan grandes inventos y progresos tecnológicos en la comunicación; las fuerzas económicas y sociales se ven fortalecidas, surge el capitalismo y la burguesía, acompañadas de nuevas entidades políticas que promovieron la consolidación de naciones y estados. Los cambios bruscos, violentos y decisivos hicieron de esta una época de reformas, descubrimientos y revoluciones a escala mundial. Algunos de los cambios más importantes se deben a la apertura de las rutas oceánicas, a la re- 
volución científica, la ilustración, la revolución industrial, burguesa y liberal, que en su conjunto dieron pie a la revolución francesa y las luchas de independencia en América.

El humanista Juan Luis Vives (1492-1540), uno de los pedagogos más importantes del siglo XVI, publicó en 1523 y 1528 dos textos: La formación de la mujer cristiana y Los deberes del marido. En el primero describió una doctrina de la educación femenina dirigida a doncellas, mujeres casadas y viudas; estableció ideas, preceptos, costumbres y normas que, según él, toda mujer cristiana desde el momento del nacimiento debía seguir (Beltrán, 1994). Este se considera el primer tratado sistemático sobre la condición femenina; despertó un inusitado interés por el tema e influyó fuertemente en el ejercicio de los educadores de la época, marcando pautas notables y significativas en muchos escritores posteriores. Se realizaron cuarenta ediciones del libro en el siglo XVI y fue traducido a cinco idiomas (Cura, 2011). En parte del texto se expone:

En el momento de la vida en el que la joven muestre ya su aptitud para las letras, debe empezar el aprendizaje de aquellos que atañe tanto a la educación del espíritu como al cuidado de la casa (Vives, 1523: 45).

¿Qué otro quehacer realizará con mayor y mejor capacidad cuando esté libre de las labores domésticas? Puede que pase el día hablando con hombres o con otras mujeres; pero, ¿de qué temas?, ¿estará siempre fuera de conversación?, ¿jamás llegará a callarse?..., el pensamiento de la mujer es ágil y por lo general, voluble, impreciso, inexperto y no alcanzo a saber hasta qué extremo llega su inconsistencia (Vives, 1523: 46).

Para aprender a hablar no pongo ningún límite, tanto en el caso del varón como en el de la mujer, excepción hecha de aquél que conviene que esté muy instruido y conozca múltiples y variadas materias que redunden en su propio provecho y en el del Estado...Yo quiero que la mujer se ciña exclusivamente a aquella parte de la filosofía que se ha ocupado de la formación de las costumbres y de mejorarlas (Vives, 1523: 63).

Las ideas básicas que presenta el libro se describen en tres aspectos: a) cómo concebía Vives a la mujer cristiana, b) cómo debía comportarse, y c) qué educación debía recibir. Estos aspectos son considerados muy conservadores, discriminatorios y falsos sobre el papel de la mujer en el ámbito familiar, social y educativo (Beltrán, 1994). Otro argumento que el autor sostiene con determinación los podemos apreciar de manera textual:

La mujer debe aprender para ella sola o, a lo sumo, para sus hijos, mientras son todavía pequeños..., porque no es adecuado que una mujer esté al frente de una escuela, ni que trabaje entre hombres o hable con ellos... Si ella es virtuosa, le conviene más quedarse en casa y mantenerse alejada de los demás; pero si se encuentra en alguna reunión, con los ojos bajos guardará recatadamente silencio, de manera que la vean algunos, pero sin que nadie la oiga. Por consiguiente, puesto que la mujer es un ser débil, con juicio inseguro y 
proclive a ser engañada (algo que puso de manifiesto Eva, a la que embaucó el diablo con un argumento frívolo), no conviene que ella enseñe, no sea que, después de aceptar una falsa opinión sobre un tema, la transmita a los oyentes con la autoridad propia del docente y arrastre a los demás fácilmente a su propio error (Vives, 1523: 64).

Aunque progresista para su momento histórico, actualmente este texto resulta controversial, por discriminatorio (Cura, 2011). Que las mujeres debían aprender y ser educadas, era una cuestión criticada entonces, pero el autor pensaba que a través de la educación ellas podrían adquirir buenas costumbres y vivir de manera decente, si encontraban un buen esposo. Por otro lado, en Los deberes del marido, Vives indica las normas fundamentales de convivencia en el matrimonio; detalla algunas prácticas, ideas, pensamientos que todo hombre debe tener en su vida cotidiana; además, sostiene algunas ideas de la superioridad masculina en aspectos físicos, de inteligencia y de educación.

Para que un hombre pueda contraer matrimonio, éste debe conocer el carácter femenino, a través de rasgos fisiológicos (salud quebradiza, debilidad, timidez, avaricia, todo ello derivado de su naturaleza fría) y psicológicos (inseguridad, suspicacia, irritabilidad, locuacidad etc.); a través de este conocimiento se evitará la decepción de la mujer. Los defectos propios de la mujer se deben moderar y reconducir convenientemente, para que puedan tener efectos positivos para la vida en común (Vives, 1523: 60).

Algunos estereotipos sexistas del autor tienen que ver con la fisiología femenina, para él las mujeres deben estar sometidas al poder y a la autoridad del marido (Beltrán, 1994). La importancia de los textos de Vives radica en las aportaciones que hace en el ámbito de la educación (Franco, 2008), así como en las ideas que reinaban en esa época sobre el papel de hombres y mujeres (Cura, 2011).

Un siglo después de la publicación de los textos de Juan Luis Vives; surgen las aportaciones del filósofo francés François Poulain de la Barre (1647-1723), quien estaba convencido de la injusticia y desigual condición en que se encontraban las mujeres de su época, por lo que escribió numerosos textos en defensa de la igualdad entre los sexos. En 1674 publicó De la educación de las damas; en el que cuestionó el sistema educativo que, según él, era injusto y discriminatorio para las mujeres; además criticó de manera tenaz la jerarquización del conocimiento, la práctica de la ciencia, la estructura y el ejercicio de los poderes públicos y religiosos, así como las ideas dominantes sobre la superioridad de un sexo sobre el otro.

La doctora Pilar Albertini (2008) supone que la principal tesis de Poulain fue que el cerebro no tiene sexo, que el conocimiento y la educación debía ser accesible a todos por igual y que, por tanto, todos pueden participar en la vida pública; además de ser el primer pensador que hizo de la igualdad una categoría fundamental de la filosofía 
social, opuesta a la idea de la igualdad natural, que supuestamente prevaleció cuando la humanidad vivió condiciones pre-sociales y pre-políticas.

Poulain recurrió a argumentos naturalistas para cuestionar la legitimidad de las desigualdades de género, rango y superioridad europea, que eran casi incuestionables; aunque en sentido contrario a las ideas predominantes. Propuso un discurso donde la igualdad era, además de natural, un concepto cultural, social y político crítico (Cazés, 2007); estos y otros planteamientos los propuso mediante la utilización del método de Descartes; sosteniendo que la diferencia entre hombres y mujeres era en realidad desigualdad, y que esta se basaba en intereses opresivos y prejuicios inaceptables. Desde esta posición, Poulain emprendió la pragmatización de las implicaciones del cartesianismo en el ámbito social, convencido de que la lucha contra el prejuicio posee un vasto potencial reformador, no solo en los planos del conocimiento racional y científico, sino también en las costumbres y en la vida cotidiana (Cazés, 2007).

A este personaje se le considera como uno de los inventores del iluminismo concepto moderno de igualdad, según Stuurman (2004); además de precursor del feminismo y de la revolución francesa. Se le debe también, según Celia y Ana Amorós (1995), el primer discurso filosófico antipatriarcal, donde argumentaba mediante una disertación política, filosófica, social, teórica y metodológica sobre la igualdad entre las personas, así como también haber formulado un discurso de visión y alcances complejos, cuyo núcleo es la igualdad entre hombres y mujeres.

En el período de la Ilustración, aparecen las propuestas del dirigente político francés, Jean Antoine Condorcet (1743-1794), un personaje de gran influencia en la Revolución Francesa, elegido miembro de la Asamblea Legislativa de Francia y presidente de esta Cámara en 1792. Elaboró un programa de instrucción pública para diseñar el sistema educativo francés (1792); en el mismo, se ofrecía a ambos sexos la posibilidad de acceder a la educación. De igual forma propuso una solución para proporcionar a las mujeres el derecho al voto y a la ciudadanía. Condorcet comparaba la condición social de las mujeres de su época con la de los esclavos y escribió en su obra póstuma Bosquejo (1795), una tabla histórica de los progresos del espíritu humano, en la que reclamó el reconocimiento del papel social de la mujer.

Después de los acontecimientos de la revolución francesa en 1789, este político manifestó que La Declaración de los Derechos del Hombre y del Ciudadano promovía contradicciones evidentes, las cuales describió como desigualdad. Según él, la revolución había traído consigo la idea universal de la igualdad natural y política de los hombres y negaba el acceso de las mujeres (que eran la mitad de la población), a los derechos políticos y civiles; lo que en realidad significaba negar su libertad y su igualdad respecto al resto de los individuos. 


\section{Edad Contemporánea (desde finales del siglo XVIII hasta el presente)}

\section{Después de la Revolución Francesa}

La escritora francesa Olimpia De Gouges (1745-1793), es considerada también una de las precursoras del feminismo; fue fundadora de la Sociedad Popular de las Mujeres en 1791, y precursora de la Declaración de los Derechos de la Mujery de la Ciudadana en 1789, en respuesta a la Declaración de los Derechos del Hombre y el Ciudadano propuesta en la revolución francesa. Este documento reconoce y declara los derechos de las mujeres y es considerado uno de los discursos más brillantes y radicales en favor de las reivindicaciones femeninas. De Gouges reclamó un trato igualitario de la mujer con respecto al hombre en todos los aspectos de la vida, públicos y privados, entre estos el derecho al voto, a ejercer cargos en el gobierno, a hablar en público sobre asuntos políticos, a la propiedad privada, a la participación en el ejército, a tener igualdad de poder en la familia y en la iglesia, así como a la educación (Puleo, 1993).

La escritora fue acusada de intrigas sediciosas y guillotinada por haberse osado a creer y exigir que los derechos que la revolución francesa había ganado para los hombres libres y ciudadanos, fuesen aplicados también para las mujeres. Esta líder es reconocida por discutir la falsa universalidad que esconde el término de hombre, que es el real significado de varón; además por hacer referencia al paradigma de la naturaleza como fundamento de las inequidades existentes. Para ella, la situación de subordinación y discriminación que viven las mujeres es "un estado de degeneración, respecto a la armonía inicial de los sexos" (Puleo, 1993).

El sistema político que triunfó en muchas sociedades del mundo durante el siglo XVIII, fue el constitucionalismo burgués. Este sistema fue apareciendo después del período ilustrado y tenía dentro de sus premisas la exclusión de las mujeres del ámbito público bajo el argumento de supuestas aptitudes y carencias naturales, es decir, continuaban las ideas que sostenían que la mujer carecía de los atributos masculinos identificados con la racionalidad, inteligencia, capacidad de juicio y la competitividad (Nash, 2004).

La obra de Jean-Jacques Rousseau (1712-1778), El Emilio o de la educación (1762), tuvo gran influencia en las ideas y políticas de los siglos XIX y XX. Se consideraba este libro un tratado pedagógico que expresaba las bases de la educación de las niñas y los niños. Las supuestas diferencias de naturaleza y de responsabilidades entre hombres y mujeres que Rousseau planteó, promovieron la idea de la superioridad de unos sobre otras. Según su tesis, las niñas debían aprender cuestiones domésticas y religiosas, mientras que los niños debían educarse para la vida pública, los trabajos de las armas y las leyes. Rousseau sostenía que madres debían enseñar a las niñas a cocinar y coser; las niñas debían abandonar los centros escolares a los ocho años, una vez adquiridos los conocimientos básicos. Por el contrario, los niños, debían 
permanecer en la escuela para aprender matemáticas y geografía. Un dicho popular resumía la perspectiva de Rousseau con la siguiente frase: "Sé buena, dulce sierva, y deja que él sea inteligente". El destino las mujeres era dedicarse al buen manejo del hogar, a la oración y a la caridad (Boix, 2005).

La escritora y feminista inglesa Mary Wollstonecraft (1759-1797), criticó fuertemente la obra de Rousseau sosteniendo que sus argumentos son pretensiosos al decir que las mujeres por su naturaleza femenina debían obedecer y que la sumisión debía inculcarse desde pequeñas. Además, que ellas adquieren valor y carácter moral cuando son hijas, esposas y madres; al respecto comenta:

El derecho al voto, al trabajo remunerativo en igualdad de circunstancias, a la no esclavitud, a la eliminación de la discriminación civil y a la educación, han sido las reivindicaciones históricas prioritarias de diversos movimientos en pro de la equidad desde sus origenes; considero que el acceso a la educación conducirá a la igualdad entre los sexos (Wollstonecraft, 1792).

Wollstonecraft protagonizó una fuerte campaña en defensa de los derechos de hombres y mujeres, pidió al Estado francés que garantizara un Sistema Nacional de Enseñanza Primaria Gratuita Universal para ambos sexos. En 1792 escribió la Vindicación de los Derechos de la Mujer, obra en la que condena la educación que se daba a las mujeres porque las hacía "más artificiales y débiles de carácter" y porque deformaba sus valores con "nociones equivocadas de la excelencia femenina". Expresó:

(...) las mujeres se encuentran tan degradadas por nociones erróneas acerca de la excelencia
femenina, que no pienso añadir una paradoja cuando afirmo que esta debilidad artificial
produce una propensión a tiranizar y da lugar a la astucia, enemiga natural de la fortaleza,
que las lleva a adoptar aquellos despreciables ademanes infantiles que socaban la estima. $\mathrm{Si}$
los hombres se vuelven más castos y modestos, y las mujeres no se hacen más reflexivas en
la misma proporción, entonces quedará claro que poseen entendimientos más débiles (53).

Mary Wollstonecraft solicitó a las autoridades de su época que reformaran las leyes para terminar con las tradiciones de subordinación femenina; sostuvo además que el Estado debía garantizar la implantación del sistema educativo. La petición más fuertemente criticada fue que se promoviera la igualdad educativa y de oportunidades para ambos sexos. El acceso a la educación permitiría que las mujeres llevaran vidas más útiles y gratificantes; en este sentido escribió: mujeres con otra educación podían haber practicado la medicina, llevado una granja, dirigido una tienda, serían independientes y vivirían de su propio trabajo" (55). En 1798, después de la muerte de Mary Wollstonecraft, su esposo William Godwin publicó el libro Los derechos de la mujer; inspirado en la correspondencia que llegaba a nombre de su esposa, por el loable trabajo en pro de la igualdad de derechos entre hombres y mujeres. 
El discurso sobre la igualdad no era importante en las políticas impuestas durante la época del constitucionalismo burgués, que legitimaba la idea sobre las diferencias físicas y biologicistas que generaban la división sexual del trabajo, su jerarquización y la consecuente discriminación; sin embargo, las autoridades sostenían que los hombres y las mujeres tenían los mismos derechos naturales, situación que creó controversias por las contradicciones políticas que facilitaron el surgimiento del movimiento feminista a inicios del siglo XIX. La exclusión de la mujer restaba solidez y coherencia al discurso filosófico y político que promovía el constitucionalismo burgués y evidenciaba otro discurso mucho más sólido que decía que la igualdad no surgía como un mecanismo natural, sino más bien construido socialmente (Rodríguez, 2007).

Una de las precursoras del feminismo contemporáneo fue la pensadora y escritora francesa de ascendencia hispano-peruana, Flora Tristán (1803-1844). En su discurso apeló al sentido de justicia universal de la humanidad, considerando que mientras las mujeres en el mundo fuesen tratadas como seres inferiores, serían siempre oprimidas y no obtendrían un bienestar universal. Su aportación al tema de derechos educativos y laborales lo hizo a través de su libro Unión Obrera (1843); aquí hace un llamado a la necesidad de una unión obrera que promoviera la educación de las mujeres, ya que a través de la mejora intelectual, moral y material es como la clase obrera podría progresar (De Miguel y Romero, 2003). Esta luchadora y autodidacta, fue víctima de violencia familiar por su esposo; además tuvo que soportar una carga social del sistema patriarcal francés, al conseguir de forma institucionalizada, su libertad legal a través del divorcio; esto en una época en la que los pilares del código napoleónico prescribían la eterna minoría de edad de la mujer casada. Su lucha incesante por conseguir una sociedad más justa e igualitaria quedó intensamente plasmada en su obra; su compromiso con los movimientos obreros y feministas propiciaron la aparición de la Unión Obrera (De Miguel y Romero, 2003).

\section{El feminismo en Inglaterra y en los Estados Unidos de América}

A inicios del siglo XIX, se empieza a evidenciar en Estados Unidos el trabajo de varias mujeres feministas, entre ellas la profesora Lucretia Coffin Mott (1793-1870), que se inspiró en la defensa de sus derechos al descubrir que sus compañeros profesores recibían el doble de sueldo que ellas. En 1848, junto a Elizabeth Cady Stanton (18151902), organizó la Primera Asamblea en Defensa de los Derechos de la Mujer en Nueva York; para este evento Stanton redactó la Declaración de Seneca Falls, conocida como la Declaración de Sentimientos, en la que propuso una resolución que exigía el derecho al voto para las mujeres.

La escritora y abolicionista Harriet Beecher Stowe (1811-1896), autora de La Cabaña del Tío Tom (1850-1852), contribuyó con sus escritos a la cristalización de los sentimientos militantes contra la esclavitud y al desencadenamiento de la guerra civil en 
pro de los derechos civiles. En su novela hizo severas denuncias sobre la esclavitud y la discriminación de mujeres y hombres de raza negra.

De igual forma la profesora Lucy Stone (1818-1893), abogó en sus clases en contra de la esclavitud y a favor de los derechos de la mujer. Como protesta contra las leyes discriminatorias, mantuvo su apellido paterno al casarse, en contra de la costumbre anglosajona de cambiarlo por el del marido. Esta líder fue la responsable de unir al movimiento feminista a Susan B. Anthony (1820-1906), una destacada reformadora social y dirigente de la lucha por el sufragio femenino. Al reunirse Susan B. Antony y Elizabeth Cady Stanton, en 1851, comenzaron una lucha por la defensa de los derechos de las mujeres. Desde 1854 hasta 1860 propugnaron la reforma de las leyes discriminatorias del Estado de Nueva York, pronunciaron conferencias y organizaron campañas para modificar la legislación existente. Su objetivo primordial era conseguir el sufragio universal y denunciar las injusticias que sufrían las mujeres.

Por otra parte, la escritora Harriet Taylor Mill (1808-1858), promovió ensayos sobre la situación de la mujer y el matrimonio. En su artículo La emancipación de la mujer (1851), establecía bases para el sufragio femenino, reclamando una plena ciudadanía política y legal para las mujeres inglesas. Como sus contemporáneas feministas americanas, Harriet Mill comparaba a los hombres con los dueños de esclavos y a las mujeres como sirvientes. Sostenía que si la abolición de la esclavitud era una cuestión moral y política, no lo era menos la abolición de la opresión de la mujer. Aunque ella no ejerció actividad política, su esposo, el filósofo, economista y político inglés John Stuart Mill (1806-1873), expresó en su ensayo La Esclavitud Femenina (1869), algunos de los errores más comunes acerca de la situación del sexo masculino y la del femenino, argumentando el por qué se dan las relaciones desiguales entre ambos sexos. Stuart Mill se destacó por defender aquellas prácticas que creía eran más acordes con la libertad individual. Recalcó que la libertad podía estar amenazada tanto por la desigualdad social, como por la tiranía política; ideas que expuso en su libro Sobre la Libertad (1859), mismo que escribió junto a su esposa. Es considerado uno de los primeros y más acérrimos defensores de la liberación femenina.

Los puntos principales de La Esclavitud Femenina (1869) se centran en comprender la naturaleza y los límites del poder, que puede ser legítimamente ejercido por la sociedad sobre el individuo. Este libro es considerado una de las obras más antiguas en el campo del feminismo defendido por hombres. Mill expuso que la opresión de la mujer era uno de los pocos vestigios conservados procedentes de modelos sociales obsoletos, un conjunto de prejuicios que impedía arduamente el progreso de la humanidad. Un argumento desarrollado por el matrimonio Mill Taylor, fue el principio de Indemnidad, mismo que decía que toda persona debería ser libre para comprometerse a realizar las conductas que desee, siempre y cuando no dañe a los demás. En este sentido, la desigualdad debería sustituirse por lo que denominaron igualdad perfecta, sin privilegios, poderes o incapacidades para cada uno. 
Creo que las relaciones sociales entre ambos sexos, aquellas que hacen depender a un sexo del otro, en nombre de la ley, son malas en sí mismas y forman hoy uno de los principales obstáculos para el progreso de la humanidad; entiendo que deben sustituirse por una igualdad perfecta, sin privilegio ni poder para un sexo, ni incapacidad alguna para el otro (Mill, 1869:9).

Stuart Mill sostiene que la desigualdad está arraigada a un sentimiento y no en la razón, además, que la situación de inferioridad de la mujer no ha sido fruto de la libre deliberación del pensamiento sino que proviene desde los primeros días de la sociedad humana, cuando la mujer fue entregada como esclava al hombre, a quien no podía resistir dada la inferioridad de su fuerza muscular; en este sentido expresó: "La relación del marido con la mujer se parece mucho a la del señor con sus vasallos; sólo que la mujer está obligada a mayor obediencia todavía para con su marido, de lo que nunca estuvo el vasallo con el señor feudal" (61).

Para el filósofo británico la única forma de realizar un análisis comparativo entre los sexos sería estudiando sociedades compuestas de hombres sin mujeres, de mujeres sin hombres, o de hombres y mujeres sin que estas estuviesen sujetas a los hombres. Ante la imposibilidad de un estudio semejante, es imposible saber algo positivo acerca de las diferencias intelectuales o morales que puede haber en la constitución de ambos sexos. En el parlamento fue considerado un radical al defender medidas como la propiedad pública de los recursos naturales, la igualdad de las mujeres, la educación obligatoria y el control de la natalidad. Su defensa del sufragio femenino en los debates sobre el Programa de Reformas de 1867 llevó a la formación del movimiento sufragista.

Por su parte, la científica Lydia Becker (1827-189o), tras asistir en 1866 a una conferencia pro-sufragio, se convirtió en activista y fundó el Comité por el Sufragio Femenino. En 1870 fundó el Diario por el Sufragio de la Mujer y estuvo como directora jefe durante una década. Becker luchó por mejorar la educación de las mujeres, en sus propias palabras sostenía que "los chicos debían también aprender a coser sus calcetines y cocinar sus propias comidas" (Cervantes, 2005). Publicó en 1870 varios artículos que sostenían que en el hogar se debían compartir las tareas domésticas y que esta no era una tarea solo para mujeres, promovió además la lucha por la educación de las mujeres y la necesidad de una reforma parlamentaria para que ellas pudieran votar, hecho que sucedió en 1884 solo para las solteras, medida que fue transitoria (Cervantes, 2005).

\section{El socialismo feminista en Alemania}

Los precursores del socialismo científico, Karl Marx (1818-1883) y Friedrich Engels (1820-1895), establecieron las bases del pensamiento socialista sobre la cuestión de la mujer. Engels en su libro El origen de la familia, la propiedad privada y el Estado (1884) equiparaba la dominación de clase, con la dominación de la mujer por el hombre. Sin 
embargo, para ambos la emancipación de la mujer sólo se haría realidad tras una revolución socialista que liquidara el capitalismo. La lucha de las mujeres debía subordinarse y articularse a la lucha de clases, ya que no había diferencia alguna entre sus objetivos. Para Marx y Engels la igualdad política entre los sexos era una condición necesaria para la plena emancipación de la sociedad; además comprendían que la base fundamental de la emancipación femenina era su independencia económica frente al hombre. Friedrich Engels (1884) se refiere a este tema en varias partes de su obra:

Una de las ideas más absurdas que nos ha transmitido la filosofía del siglo XVIII es la opinión que en el origen de la sociedad, la mujer fue la esclava del hombre. Entre todos los salvajes y en todas las tribus que se encuentran en los estadios inferior, medio y en parte, hasta superior de la barbarie, la mujer no sólo es libre, sino que está muy considerada (Engels, 1884: 49).

(...) El primer antagonismo de clases que apareció en la historia coincide con el desarrollo del antagonismo entre el hombre y la mujer en la monogamia; y la primera opresión de clases, con la opresión del sexo femenino por el masculino (Engels, 1884: 65).

La situación no es mejor en lo concerniente a la igualdad jurídica entre hombre y mujer en el matrimonio. Su desigualdad legal, que hemos heredado de condiciones sociales anteriores, no es causa, sino efecto, de la opresión económica de la mujer (Engels, 1884: 73).

La mujer es un ser libre e inteligente y como tal, responsable de sus actos, lo mismo que el hombre; pues, si esto es así, lo necesario es ponerla en condiciones de libertad para que se desenvuelva según sus facultades. Ahora bien, si relegamos exclusivamente a la mujer a las funciones domésticas, es someterla, como hasta aquí, a la dependencia del hombre, y, por lo tanto, quitarle su libertad. ¿Qué medio hay para poner a la mujer en condiciones de libertad? No hay otro más que el trabajo (Engels, 1884: 166).

El destacado político socialdemócrata alemán Augusto Bebel (1840-1913), escribió un importante estudio sociológico titulado: La mujery el socialismo, en 1879. Su doctrina política, en la que sobresale la praxis sobre la teoría, quedó reflejada en este libro, que se convirtió en una obra de referencia para todos los socialistas alemanes. El texto ayudó a la formación de varias generaciones de marxistas y llegó a editarse cincuenta veces en poco más de treinta años. Bebel posee el mérito de ser el primer teórico marxista que escribiera en forma específica sobre la mujer. En este libro explica las raíces profundas de la opresión de la mujer, las formas que adoptó a lo largo de los siglos, el significado históricamente progresivo de su integración en la producción industrial y la necesidad de la revolución socialista para abrir el camino a la liberación de la mujer: "La mujer de la nueva sociedad será plenamente independiente en lo social y lo económico, no estará sometida lo más mínimo a ninguna dominación, ni explotación; se enfrentará al hombre como persona libre, igual y dueña de su destino" (Bebel, 1879). 
Un grupo marxista dirigido por Bebel propuso en el Congreso de Gotha en 1875 el programa denominado La igualdad del hombre y de la mujer; que fue denegado, ya que el congreso afirmó que las mujeres no estaban preparadas para ejercer sus derechos: eran consideradas criaturas inferiores, cuyo lugar predestinado era el hogar. El discurso del congreso consistía en asegurar al marido un salario adecuado para abastecer a toda la familia, esto haría que las mujeres regresaran a su hábitat natural y no pretenderían obtener un trabajo que las alejara del hogar (Bebel, 1879). Las relaciones de familia, según Bebel, se transforman en un temor para los modos de producción y la desigualdad social de la mujer es una consecuencia del imperio de la propiedad privada, representando esto el comienzo de la humillación y el desprecio por la mujer. De ahí que la emancipación de ellas constituya una parte del problema de poner fin a la explotación y a la opresión social (Bebel, 1879).

Dentro de la socialdemocracia alemana, figura también la maestra Clara Zetkin (1857-1933), quien en 1892 decide dedicarse a escribir en la sección femenina del Diario Social Demócrata llamado La Igualdad, constituido totalmente por mujeres y considerado el primer órgano de mujeres socialistas en Alemania. Fue una de las precursoras del feminismo alemán, incansable en su lucha a favor de la paz en el mundo (CIMTM, 2009). Clara Zetkin expone en uno de sus artículos que "como persona, como mujer y como esposa, la mujer no tiene la menor posibilidad de desarrollar su individualidad. Para su tarea de mujer y madre sólo le quedan las migajas que la producción capitalista deja caer al suelo" (Zetkin, 1892; en Ibarra, 2011).

En 1910, Zetkin organiza la Primera Conferencia Internacional de la Mujer en Copenhague; allí plantea el establecimiento del 8 de marzo como el Día Internacional de la Mujer, propuesta ampliamente aprobada por las 174.751 afiliadas en 1914 . Años más tarde, Zetkin se une a Rosa Luxemburg (1871-1919) en actividades para detener algunos acontecimientos de la Primera Guerra Mundial en su país, por este motivo fue encarcelada en varias ocasiones. Fue diputada desde 1920 hasta 1933. Sus intervenciones siempre fueron admiradas, en especial cuando en 1932 se opuso rotundamente a la criminal ideología de Adolfo Hitler. Cuando este toma el poder ella solicita exilio en Rusia en 1933; más tarde es nombrada presidenta de la Junta Internacional de Mujeres en ese país.

\section{El feminismo del siglo XX y su lucha por la equidad}

El feminismo como movimiento social y político surge de las filas de una corriente de pensamiento que aún incipiente marcaría radicalmente una diferencia en el modo de ver la vida y la sociedad en la época moderna: la Ilustración. Este movimiento se fue gestando a partir de un proceso de reflexión en torno a la resignificación de la idea ilustrada de la igualdad (Flores, 2004). 
Históricamente el movimiento feminista surge como heredero de este proyecto cultural y político que en el siglo XVIII se denominó ilustración o siglo de las luces, en donde las feministas utilizaron el mismo argumento ilustrado, el logos, para vindicar ciertos criterios universalistas como el concepto de ciudadanía (Valcárcel, 1991). En las sociedades occidentales los movimientos feministas se asocian fundamentalmente con la lucha por la obtención del sufragio femenino, en el marco de las doctrinas liberales que reconocían la necesidad de conceder a todos los ciudadanos, sin distinción de sexo, la igualdad de derechos políticos (Puleo, 2000; Lamas, 2007).

Tras la efervescencia feminista de las primeras décadas del siglo $\mathrm{XX}$, los años cuarenta a sesenta se caracterizan por la decadencia del movimiento de liberación de las mujeres. Tras la Segunda Guerra Mundial, la sociedad conservadora ideológica y social que emergía, dominó y reafirmó la visión tradicional de las mujeres como esposas, madres y amas de casa (Flores, 2004).

La transformación que ha tenido el concepto de equidad proviene en gran parte de las luchas que se protagonizaron a finales del siglo XIX y principios del siglo XX, por el movimiento feminista denominado de primera ola. El concepto emerge de la expresión francesa feminisme en 1837, y fue un movimiento que intentó apoyar públicamente los derechos de las mujeres. En la actualidad el feminismo es considerado una ideología y un conjunto de movimientos políticos, culturales y económicos que tienen como objetivo la igualdad de los derechos de las mujeres y de los hombres. Con ello el movimiento feminista crea un amplio conjunto de teorías sociales, entre algunas de ellas: la teoría feminista que ha dado lugar a la aparición de disciplinas como la geografía feminista, la crítica literaria feminista, la historia feminista; así como una amplia variedad de tendencias como el feminismo cultural, liberal, radical, el anarcofeminismo, el feminismo de la diferencia, el ecofeminismo, el feminismo marxista, el separatista, el feminismo filosófico, el cristiano, el feminismo lésbico, el feminismo islámico, el feminismo post-colonial, o el feminismo crítico.

El feminismo de la primera ola es definido como la oposición moral a la dominación masculina (Jaggar, 1999). El movimiento feminista de esta época se destacaba por la lucha constante por demostrar cómo el discurso político, filosófico, moral, educativo, cultural, sociológico y hasta religioso, había sido formulado desde la primera persona del masculino, es decir, desde la perspectiva dominante conocida como androcentrismo, que sostenía que los modos de pensar en todos los ámbitos de las sociedades estaban descritos por y para los hombres.

Una de las primeras y quizás la más conocida feminista, fue la escritora, novelista y catedrática francesa Simone de Beauvoir (1908-1986). Es reconocida por sus obras, que reflejan una visión reveladora de su vida y de su tiempo. Sus textos fueron caracterizados como polémicos y rechazados por su adscripción a la corriente existencialista francesa. Su compromiso político la llevó a formar parte de la resistencia francesa contra la inva- 
sión nazi alemana (Castany, 2004). En su libro más emblemático, Le deuxième sexe, (El Segundo Sexo, 1948-1949), publicado poco después de la Segunda Guerra Mundial; hace un profundo análisis y reflexión documentada sobre el papel de las mujeres en la sociedad francesa (CIMTM, 2009). Sostiene que si las mujeres son consideradas inferiores a los hombres no era por cuestiones de nacimiento, sino que se volvían inferiores tras un adoctrinamiento cultural disfrazado de determinismo biológico.

En el primer volumen de su libro que tituló Los hechos y los mitos, Beauvoir analiza las diferencias biológicas, psicoanalíticas, la historia de la humanidad en su fase de primitivismo, propiedad privada y revolución; para terminar con los mitos y el papel que desempeñan en la formación de la ideología sobre las mujeres: "La mujer no se reivindica como sujeto, porque carece de los medios concretos, porque experimenta el vínculo necesario que la sujeta al hombre sin plantearse la reciprocidad, y porque a menudo se complace en su papel de otro" (1949:7). El segundo volumen, La experiencia vivida, muestra las etapas de formación de las mujeres desde la infancia, juventud, iniciación sexual, madurez y vejez; también considera la situación de las mujeres casadas, madres, así como las prostitutas (Albertini, 2008).

Beauvoir eligió el título del Segundo Sexo, porque desde su planteamiento filosófico, las mujeres eran consideradas como el sexo en segundo lugar, después del varón, con una identidad construida en función del otro, el hombre. El libro es considerado como el ensayo feminista más importante del siglo XX, presenta una teoría que explica la subalternidad femenina desde pautas culturales de la civilización y no en términos de la naturaleza biológica. Tuvo una visión de futuro al considerar que era necesario un cambio en el orden social, que las mujeres transformaran su pasividad por un rol más activo, siendo protagonistas de su propia historia y de su libertad (Albertini, 2008).

La jerarquía de lo masculino sobre lo femenino era para las feministas de esta primera ola, el principal obstáculo para que las mujeres salieran de esta situación de desventaja, en cuanto a que lo femenino como sexualidad equivalía a hembra y lo masculino a macho. Si se rompía con dichos parámetros de pensamiento y se repensaba por separado en el sexo hembra y género femenino, las ataduras a roles específicos podrían empezar a romperse (Granados, 2006).

Simone de Beauvoir y Betty Friedan (1921-2006), escritora y psicóloga feminista estadounidense, son destacadas personalidades en pro de los derechos de las mujeres a principios de los años 70 . Friedan aportó a la discusión del feminismo al desenmascarar en su libro La mistica femenina (1963), la falsa idea que la mujer se realizaba completamente en su función de esposa, madre y reina del hogar (Tedeschi, 2013). Con este trabajo fue galardonada con el premio Pulitzer en 1964. El libro fue resultado de entrevistas realizadas a mujeres de diversas edades y profesiones, así como expertos en psicología, psicoanálisis, antropología, educadores y muchos otros. Friedan realiza un exhaustivo análisis sobre el rol de las mujeres de clase media, convertidas en amas 
de casa sin recursos propios. Este texto, junto a El segundo sexo de Beauvoir, es referente indispensable para la configuración del movimiento feminista de la década de 1970; ya que no sólo se limitaron a conceptualizar y considerar la problemática femenina desde un punto de vista sexual, sino también la analizaron como una cuestión de identidad.

En 1966 Betty Friedan y 27 hombres y mujeres, sentaron las bases de la Organización Nacional para las Mujeres (NOW en inglés); organismo que presidió hasta 1970. Como fundadora y dirigente de esta organización, Friedan tomó posiciones extremas en asuntos como la igualdad de salarios, las oportunidades de promoción y otros derechos que hoy son ley, pero que entonces no se ejercían para ambos sexos.

El feminismo de la primera ola se caracterizó por la lucha por la igualdad, en particular de derechos, la prohibición de la discriminación en el trabajo, la revocación de las leyes contra el aborto, la igualdad de género en aspectos políticos como el derecho al voto, el trabajo en igualdad de circunstancias y el derecho a la educación. Sin embargo, los movimientos sociales y políticos ocurridos en Francia en 1968 inauguraron la segunda ola del feminismo. Tanto en Francia como en el resto del mundo, este nuevo movimiento se caracterizó por un cambio en las prioridades. La búsqueda de la igualdad es sustituida por una afirmación de la diferencia. Dicho de otro modo, ya no era el objetivo principal ser consideradas como iguales, sino ser reconocidas como género diferente, con necesidades distintas, pero con las mismas oportunidades (Granados, 2006).

Las feministas no pretendían que la mujer fuera lo contrario al hombre; buscaban ser un otro verdadero, el reconocimiento de su particularidad como género y no solo como opuesto a masculino. Esta segunda ola fue en muchos sentidos una respuesta en contra del feminismo de la primera ola, que no reconocía la diferencia, sino que se afirmaba como igual al hombre. El discurso de los polos opuestos quedaba atrás. En este sentido, es la misma Betty Friedan quien escribe un texto al que denominó La segunda fase (1981); aquí incluye a los hombres y a los niños como sujetos que acompañan a las mujeres. Señala que la cuestión de la igualdad es un hecho que está siendo transformado y que existe una nueva realidad personal y política para mujeres y hombres.

En un primer momento, la lucha estaba centrada a conseguir participación total, poder y voz activa de las mujeres en procesos políticos, sociales, laborales, sexuales y reproductivos etc. En ese sentido el primer estado está logrado. Ahora viene el segundo estado, en el que se vislumbra a las mujeres dentro de una familia y trabajo. Este segundo estado no es una lucha contra los hombres. Se debe poner atención en aspectos como la división de responsabilidades en relación a los hijos y al trabajo doméstico. El feminismo de este segundo estado debe enfrentarse a la familia con una actitud diferente y adaptarse a la revolución moderna, con una mirada de equiparación de derechos y responsabilidades para ambos sexos (Friedan, 2000). 
Según Susana Tedeschi (2013), Betty Friedan fue una mujer adelantada a su tiempo, nunca bajó la guardia en los problemas que siempre la preocuparon: la reestructuración de lo doméstico-familiar y la paridad económica-laboral entre hombres y mujeres, dos frentes en los que abrió brecha y que la convirtieron en la figura más emblemática del feminismo en la década de 1960, en la que todo estaba por hacer. Beauvoir y Friedan serán recordadas como dos de las activistas que más contribuyeron a trazar un camino hacia la igualdad real entre los géneros (Bébel, 2004).

En una entrevista realizada a Betty Friedan en el año 2000 por Isabel Martínez Lozano, la activista arremetió contra la concepción paternalista de la vida femenina, que define como "confortable campo de concentración” y contra la mística de su estatus de sometimiento y dominio. Insistió especialmente en que esa mística de la feminidad es producto de un sistema económico muy concreto y no del resultado del instintivo afán de dominio de un sexo sobre otro. Aquí señaló:

Lograr una paridad de género con respecto a los ingresos es la principal prioridad para lograr la igualdad en su totalidad. La igualdad económica es una gran necesidad para las mujeres. Tener un empleo que brinda ingresos significa que la mujer puede tener además una fuerza más igual en el proceso político. Pero los ingresos no constituyen el único beneficio que las mujeres encuentran en el trabajo. Más allá de lo monetario es imprescindible formar parte del trabajo continuo de una sociedad. No obstante, los ingresos son algo tan importante en la sociedad actual que de ellos depende la igualdad o la exclusión (Friedan, 2000).

La tercera ola feminista comienza en los años 90 y se extiende hasta la actualidad; constituye una continuación y una reacción a las lagunas que se perciben en el feminismo de la segunda ola. Según Verónica Granados (2006) es difícil hablar de una tercera ola, principalmente en países en vías de desarrollo donde en muchos ámbitos siguen sin superarse los dilemas de la primera ola. Todavía en Francia, Estados Unidos y el Reino Unido, países que han contribuido enormemente al acervo feminista, los dilemas de la primera y segunda ola son motivo de intensos debates.

La tercera ola feminista intentaría una espiritualización ética del contrato social, donde la mujer siga siendo reconocida como una alteridad radical, un "otro" diferente del hombre y no su opuesto. Dicho de otra manera, el género femenino no es contrario al masculino, es diferente, y el reconocimiento de esta diferencia implica responsabilidad y no lucha (Granados, 2006).

De alguna manera la tercera ola está marcada por el fenómeno de la posmodernidad, en el que las fronteras han sido rebasadas y las tecnologías de la información y la comunicación llegan a rincones remotos del mundo. La desaparición de fronteras reales e imaginarias ha generado una necesidad de reconocimiento de la diferencia como respeto y responsabilidad hacia todo lo que se sale del marco de la identidad 
misma. En este sentido, los hombres y las mujeres deberían estar en igualdad de representación en los sistemas políticos, hecho que se traduce en igualdad al acceso del poder; así mismo, deberían repartirse equitativamente las funciones domésticas y la educación de los hijos/as. El feminismo de la tercera ola significa que hombres y mujeres son iguales, pero diferentes, dentro de las complejidades de cada género. Es importante identificar que este nuevo movimiento es multifacético, multidimensional y multicultural, pero al final sigue luchando por el principio básico de la igualdad (Biswas, 2004).

El movimiento feminista, como lo afirma Alicia H. Puleo (2000), ha sido un poderoso estímulo en muchos aspectos y un gran aporte para las ciencias sociales.

El feminismo, que comenzó reivindicando un lugar en el espacio público para las mujeres, la reivindicación de ciudadanía en la revolución francesa, el derecho al sufragio en el siglo XIX, ha terminado cuestionando los conceptos clásicos de lo público y lo privado, y ha llevado al espacio público temas que se han considerado exclusivos del espacio privado (planificación familiar, aborto, violencia doméstica, etc.), ensanchando de este modo el ámbito de la política (Puleo, 2000:5).

El feminismo, como teoría y como movimiento ha producido cambios en la sociedad y estos, a su vez, han incidido en el discurso filosófico y científico. Sin embargo, el feminismo contemporáneo es un proyecto pluralista y diverso en el que coexisten diferentes posiciones ideológicas y vitales, materializadas en las diferentes corrientes del feminismo: reformista, radical, revolucionario, socialista, marxista, de la igualdad, de la diferencia, ecofeminismo, entre otros (Puleo, 200o).

La aportación más valiosa del feminismo liberal, del que formaron parte Simone de Beauvoir (1949), Betty Friedan (1984), el grupo NOW, Gloria Steinen, Bella Abzug (1995), entre otras, consistió en afirmar la igual capacidad de ambos sexos en la lucha por defender la presencia de la mujer en ciencia, política y economía; además de oponerse a todos los atropellos que las mujeres seguían siendo sometidas, desde la familia, el Estado o el mercado. Sus preocupaciones se centraron básicamente en la lucha contra la discriminación de que eran objeto en la práctica social, y en la identificación de los mecanismos que sustentaban la subordinación del sexo. Pero el feminismo actual, supone una gran aportación al mundo científico. El propósito de este nuevo movimiento es lanzar un reto a la sociedad y la construcción del cuerpo teórico de las ciencias sociales que tome en cuenta de manera igualitaria, las aportaciones de hombres y mujeres en la vida pública, es decir, en todos los campos de actuación del ser humano. 


\section{La equidad de género en la legislación nacional e internacional}

Los principios, declaraciones, legislaciones, tratados y garantías nacionales e internacionales, enuncian que todos los ciudadanos (hombres y mujeres) deben gozar de los mismos derechos; entre ellos, el de la educación. Esta no solo dignifica al ser humano en su interioridad, sino que lo transforma definitivamente; le permite decidir, opinar, le proporciona mejores condiciones de vida, no solo porque posibilita el acceso a nuevas formas de conocimiento, laborales y de oportunidades, sino porque los aísla de las discriminaciones y los invita a sentirse iguales y ser realmente libres. La libertad consiste en la posibilidad de gozar de los mismos derechos y las mismas oportunidades en todos los planos de su existencia.

Este apartado hace una breve reseña de algunos documentos que tratan de manera directa o transversal diversas temáticas relacionadas con la equidad e inequidad de género. Los mismos se describen de forma cronológica, destacando la fecha de su creación, lugar, organismo, instituciones o grupos sociales que los produjeron, así como una síntesis sobre cada documento. A partir de este análisis es posible comparar cómo el concepto de equidad de género evolucionó hasta convertirse en un tema obligado en las agendas, no solo en el ámbito político, sino en todas y cada una de las áreas del quehacer humano. En el anexo $\mathrm{N}^{\circ} 1$ se ofrece un panorama general en materia de legislaciones a nivel internacional, regional, nacional, estatal y local, para conocer históricamente algunos avances y transformaciones en materia de equidad de género. El anexo $\mathrm{N}^{\circ} 2$ presenta algunas de las leyes, planes, artículos y convenios interinstitucionales establecidas en México que promueven la equidad de género y sancionan todas las prácticas discriminatorias.

La equidad de género requiere que todas las dimensiones de la justicia incorporen la perspectiva de género en los documentos legislativos, con el objetivo de combatir las discriminaciones, la desigualdad, la opresión y la violencia contra hombres y mujeres. En la actualidad algunos autores (Gilligan, 1982; Goets, Nyamu- Musembi y Jenkins, 2007; McWilliam y Leigh; citados en Mukhopadhyay y Singh, 2007), utilizan el concepto de justicia de género para referirse a la búsqueda de la autonomía y los derechos de los seres humanos; el mismo revela una posición política, un conjunto de convicciones acerca de lo que es correcto y bueno en las relaciones humanas, y la manera como estos resultados deseables se pueden lograr. La justicia de género puede definirse como el final de las desigualdades entre mujeres y hombres, tomando medidas para reparar las desventajas que llevan a la subordinación de un sexo sobre el otro (Goetz, 2007:3).

La justicia de género incluye elementos únicos que van más allá de conceptos relacionados con justicia en cuanto a clase, raza, posición social, etc. El género impacta estas y todas las demás categorías sociales, produciendo diferencias en los intereses y las concepciones de justicia entre las mujeres y los hombres. En este sentido, los siste- 
mas de administración de justicia deben promover la justicia de género e incorporar los derechos humanos con perspectiva de género en las políticas públicas y sociales nacionales e internacionales.

La inequidad de género, junto a otros fenómenos sociales, es uno de los elementos claves que están presentes en la cultura y en los modos de pensamiento de nuestra sociedad (Santos, 1998). Gran parte del problema de violencia de género se debe a la interpretación equivocada del concepto de género, que en muchas ocasiones se confunde con el sexo. Según Anthony Giddens (1989), el sexo está constituido por "las diferencias anatómicas y biológicas que distinguen a las mujeres y a los hombres". Otra cosa es el género que, en términos sencillos y complementarios es definido por Light, Keller y Calhoun (1991) como "todas las características no biológicas asignadas a hombres y mujeres". En otras palabras, el género es un eje sobre el que se apoya la reflexión sobre el modo de vivir y de comportarse como hombres y mujeres en una sociedad (Santos, 2008).

Buena parte de los problemas que trae consigo la práctica de inequidades de género en la escuela radica en la supresión de esa diferencia o en la interpretación y utilización de ella. Por muchos años se han considerado naturales muchas diferencias que nacían de las expectativas, exigencias, mitos, intereses y costumbres de la sociedad. No obstante, puede decirse que la cultura es responsable de crear gran parte de la diferenciaciones de género (Navarro, 2004).

Cada sociedad plasma en un sistema de género los comportamientos y las relaciones entre hombres y mujeres con pautas y modelos; los roles femeninos y masculinos se transmiten y refuerzan en la familia, escuela, comunidad, etc., pero estas formas de comportamiento, que muchas veces son impuestas por una sociedad y cultura determinada, responden a características específicas de clase, etnias, religión, entre otros grupos. Los roles que tradicionalmente se atribuyen a mujeres y hombres no son innatos, ni naturales; sino aprendidos, por lo tanto son cuestionables y modificables (Urruzola, 2003). En este sentido Araya (2003) comenta:

Los roles son continuamente redefinidos por la sociedad, no son totalmente estables y se van modificando en relación con los cambios sociales y las demandas ambientales, entonces; si bien algunos de ellos se transmiten y refuerzan en el ámbito escolar, su naturaleza histórico-social permite también su desaprendizaje, cuestionamiento y modificación (Araya, 2003: 15).

Los roles de género se refieren al conjunto de expectativas relacionadas con los comportamientos sociales que se esperan de las personas de determinado sexo; estas expectativas reflejan creencias, prácticas y valores sociales que hombres y mujeres asumen como propias, se transmiten tanto en nivel micro como macro social, comenzando por la familia (Navarro, 2004). Estos roles funcionan como mecanismos cognoscitivos y perceptivos en los que la diferenciación biológica se convierte en diferenciación social, 
delimita los contenidos de la feminidad y masculinidad y varían de acuerdo a la cultura, el estrato social, la escolaridad y la estructura familiar (Landero, 2003).

Existen muchos estereotipos sociales acerca de los roles masculinos y femeninos, las características atribuidas transgeneracionalmente muestran al hombre en tareas más activas y fuertes; y a las mujeres en roles relacionados con procreación, cuidado, socialización de los hijos, tareas domésticas. Sin embargo, a través del tiempo han ocurrido cambios en los roles de género, como la inserción de la mujer al mundo laboral, la libertad para decidir la propia sexualidad, el derecho a voto, mayor acceso a la educación y a la política, entre otros (Bonal y Tomé, 1997).

Por diversas razones históricas, culturales y sociales, los patrones de educación han dirigido las aptitudes de niños y niñas. En la infancia los modelos sociales ejercen una gran influencia para potenciar determinadas capacidades, gustos y aspiraciones claramente diferenciados entre el género femenino y masculino; esta diferenciación marcará en un futuro el acceso a determinados sectores de actividad profesional, así como a su posicionamiento social y cultural.

Las condiciones estructurales de las sociedades favorecen las desigualdades y obstaculizan la inserción equitativa de mujeres y hombres en la vida pública (Landero, 2003). La formación de una sociedad que no excluya a ninguno de sus miembros y proteja a los más vulnerables, es uno de los grandes retos de las sociedades modernas. Se hace necesario contribuir en nuestra sociedad al desarrollo de una cultura que respete la dignidad de hombres y mujeres en su diversidad y en sus diferencias; que garantice además su derecho a una educación equitativa e integral.

A través de este recorrido en materia de legislaciones se puede constatar cómo ha ido evolucionando el concepto de género y el papel que instituciones como la ONU y la OEA han desempeñado a lo largo de los años; además, la influencia que han tenido estos organismos internacionales en las legislaciones en México. Poco a poco se han ido moderando las leyes y preceptos que de alguna manera atentaban contra los derechos de las mujeres. De igual forma han ido surgiendo nuevos mecanismos en materia judicial para que tanto hombres como mujeres accedan a sus derechos de manera equitativa. Aunque todavía hay mucho por hacer, estas acciones son marcos de referencia para trabajar la equidad de género y para el desarrollo de políticas públicas y sociales equitativas.

\section{Desigualdades de género en la actualidad: El caso de la educación}

El artículo $1^{\circ}$ de la Declaración Universal de los Derechos Humanos (1948) destaca que: "Todos los seres humanos nacen libres e iguales en dignidad y derechos y dotados como están de razón y conciencia, deben comportarse fraternalmente los unos con los 
otros". El género es una construcción que la sociedad y la cultura imponen a hombres y mujeres por medio de ideas y representaciones que se asignan a cada sexo. Influye en todas las áreas de la vida de los individuos, en la construcción de identidad, en la conformación de valores, actitudes, sentimientos, conductas y en las actividades diferentes para cada sexo (CIJ, 2007).

La igualdad de género significa que la mujer y el hombre disfrutan de la misma situación y que tienen iguales condiciones para la plena realización de sus derechos humanos y su potencial de contribuir al desarrollo político, económico, social, cultural y de beneficiarse de los resultados. La igualdad de género es, por lo tanto, la valoración imparcial por parte de la sociedad de las similitudes y diferencias entre el hombre y la mujer y de los diferentes papeles que cada uno juega en la sociedad (CIM, 2001).

El derecho a recibir una educación primaria gratuita, sin que importe el género, la procedencia, el credo, o las aptitudes mentales y físicas; a desarrollar al máximo la personalidad, el talento y las competencias; a recibir una educación de calidad en un ambiente seguro, saludable y protector, incluso en situaciones de emergencia; forma parte del conjunto de derechos de niños y niñas que son reconocidos e incorporados en diversas convenciones internacionales, leyes y tratados regionales. La UNICEF (2009) señala que aunque el derecho de las niñas y niños a la educación está reconocido internacionalmente, en muchas partes del mundo no se ha cumplido plenamente y esto representa una promesa fragmentada que afecta directamente a estos/as, a sus familias, comunidad y al potencial de desarrollo global de los países donde viven.

La educación es un derecho humano, hace parte de la Declaración Universal de los Derechos Humanos (1948), en su artículo 26 y en la Convención de los Derechos del Niño (1989); el artículo 28 añade que debe ofrecerse en igualdad de oportunidades. En la Cuarta Conferencia Mundial de la Mujer en Beijing (1995), se especificó que se debía asegurar la igualdad de acceso a la educación de hombres y mujeres; de igual forma, esta declaración consideró la educación como un instrumento indispensable para lograr los objetivos de igualdad, desarrollo y paz en las naciones del mundo.

Sin una educación universal, los países tienen menos probabilidades de conseguir los Objetivos de Desarrollo del Milenio (ONU, 200o) y los Objetivos de Educación para Todos (UNESCO, 200o); en este sentido, la ONU propuso que la educación era una de sus metas estratégicas y que se debía lograr la enseñanza primaria universal, promover la igualdad y paridad entre los géneros, en todos los niveles de escolaridad. El Informe de Seguimiento de la Educación para Todos en el Mundo, publicado por la UNESCO (2010), indicó que se habían conseguido avances significativos desde que se adoptaron las metas de la Educación para Todos y los Objetivos del Desarrollo del Milenio; entre ellos vale la pena destacar los grandes pasos hacia la universalización de la enseñanza primaria, el incremento en el número de estudiantes en la educación secundaria y superior, en muchos países se ha conseguido la igualdad entre los sexos 
en los sistemas educativos, se han elevado los niveles de permanencia y terminación en la enseñanza primaria, entre otros.

Para la UNESCO (2015), la igualdad de género es un elemento central en la búsqueda de una sociedad justa, para ello, instituciones sociales como las escuelas son los lugares propicios para la puesta en práctica real de la plena participación de hombres y mujeres; además de ofrecer las condiciones para el desarrollo de todo su potencial. La participación total y equitativa de las niñas y los niños es vital para asegurar un futuro sostenible, en este sentido es necesario considerar que ambos pueden desarrollarse integralmente sin importar si son hombres o mujeres, ya que:

- Los roles de género son creados por la sociedad y se aprenden de una generación a otra;

- Son constructos sociales y se pueden cambiar para alcanzar la equidad de género;

- Asegurar la equidad de género entre niños y niñas significa que ambos tienen las mismas oportunidades para acceder a la escuela, así como durante el transcurso de sus estudios.

- Las desigualdades de género socavan la capacidad de las personas de ejercer sus derechos;

- Empoderar equitativamente a mujeres y hombres es una herramienta indispensable para hacer avanzar el desarrollo y reducir la pobreza.

Cifras estadísticas e informaciones del Banco Interamericano de Desarrollo (2014), UNESCO (2010), ONU (2012), reflejan una participación casi paritaria entre mujeres y hombres en los distintos niveles del sistema educativo; pero esta igualdad numérica no está acompañada de una igualdad real, dado que los procesos de enseñanza y aprendizaje se continúan desarrollando en contextos de discriminación y se manifiestan en diversos componentes que atentan contra la equidad entre los géneros.

Actualmente se utiliza un índice de Equidad de Género (IEG) para medir la brecha entre hombres y mujeres en educación, empoderamiento político y actividad económica. Esta medida establece los valores para cada área en una escala de o a 100, donde el cero significa que no existe equidad entre los géneros; por ejemplo: ninguna mujer tiene acceso a la educación, mientras que todos los hombres sí; por otro lado, 100 significa igualdad perfecta. Este índice ayuda a comprender la brecha de género en cada área establecida, a través de un promedio en cada dimensión.

En materia de educación el IEG establece la brecha existente en la matrícula en todos los niveles educativos, así como en los niveles de alfabetización de las regiones; sin embargo, la medida ofrece información sobre la paridad existente en educación, mas no en calidad o eficiencia. Investigaciones sobre esta dimensión indican que en todo el mundo la brecha de género en educación es menor que en los otros dos componentes, alcanzando un total, a nivel global, de 71, considerado bajo en la escala establecida (Raya, 2012). 
En México, por ejemplo, el IEG establece una brecha en educación de 98, esto quiere decir que aún no se alcanza una igualdad real, que indique que mujeres y hombres tienen las mismas oportunidades de acceso a los distintos niveles educativos. En cuanto a la participación económica, el índice es 42 (muy bajo); y para la participación en la toma de decisiones, el índice marca un 17, (categorizado como crítico).

La participación de la mujer en la fuerza laboral es apreciablemente menor que la de hombres. Tienen sueldos considerablemente menores por el mismo tipo de trabajo, y un porcentaje mayor de las mujeres trabaja en empleos vulnerables o irregulares. Pero lo más importante es que las mujeres no tienen en ningún país las mismas oportunidades que los hombres para participar en el proceso de toma de decisiones económicas y políticas. Las mujeres siguen en segundo plano, aunque hayan dado grandes pasos en materia de educación y participación económica. Hasta en los países donde la situación relativa de la mujer es mejor, sigue habiendo una importante brecha de género en materia de empoderamiento (Raya, 2012).

La directora general de la UNESCO (2015), Irina Bokova, subrayó que todavía quedaba un largo camino por recorrer; según ella, habían unos 759 millones de personas en el mundo que no sabían leer ni escribir y dos tercios de ellas eran mujeres. En el 2002 la UNICEF estimó que 115 millones de niños y niñas en edad escolar no asistían a la escuela primaria; para el 2008 la cifra se había reducido a 67 millones, de los cuales el $53 \%$ eran niñas (UNICEF, 2009). Se estima que asisten a la escuela primaria más del $85 \%$ de los niños y niñas del grupo de edad escolar correspondiente; en un día cualquiera, más de 1.000 millones de niños y niñas en edad escolar asisten a la escuela primaria o secundaria en el mundo. Sin embargo, persiste inquietud sobre si en realidad se ofrece calidad en los servicios educativos (UNICEF, 2009).

En general puede argumentarse que se han reducido las diferencias por razón de género que afectan a la educación primaria a escala regional y mundial, lo que ha situado el índice de paridad de géneros en países en desarrollo en un 96\% (UNICEF, 2009); no obstante, de forma lamentable, en muchas partes del mundo aún hay disparidades profundamente arraigadas. En veintiocho países en desarrollo, por cada diez varones escolarizados en primaria hay todavía menos de nueve niñas que van a la escuela. Se estima que el 54\% del total de estudiantes sin escolarizar son niñas; la matrícula en educación primaria de los niños es superior a la de ellas (UNESCO, 2010).

Datos de la CEPAL (2009), indican que la asistencia neta a la escuela secundaria en la región entre los niños es inferior en seis puntos porcentuales a la que se registra entre las niñas. Aún en los países cuyos promedios de educación primaria indican paridad, se evidencia un rezago de las niñas en las zonas rurales e indígenas (Aasen, en Eljach, 2011).

La UNESCO (2010) señala que la transición de la enseñanza primaria a la secundaria es difícil para muchos estudiantes; algunos de los obstáculos con que tropiezan en la escuela primaria suelen amplificarse en la secundaria, por ejemplo: el costo de la 
escolarización, la distancia del domicilio al centro escolar, la necesidad de trabajar y, en el caso de las jóvenes, obstáculos de índole socioeconómico, cultural y de estereotipos de género profundamente arraigados en las familias. Bajo este panorama, la inacción contra las desigualdades, la estigmatización y las discriminaciones emanadas del nivel de ingresos, la desigualdad entre los sexos, la etnia, el idioma y la discapacidad están retrasando los progresos hacia la educación para todos (UNESCO, 2010).

\section{Comentarios finales}

Desde los orígenes del ser humano, se ha distinguido que existe una notable diferencia entre los hombres y las mujeres, el papel desempeñado por los primeros ha sido sobrevalorado y el de ellas es, en ocasiones ignorado, subvalorado y hasta menospreciado.

El mundo social está lleno de significaciones. Como seres sociales estamos inmersos en culturas que nos transmiten constantemente toda una serie de sentimientos, ideas y conocimientos de la realidad; además, de forma cotidiana se categorizan las personas y sus acciones en grupos específicos en los que aprendemos a conducirnos según reglas y normas establecidas socialmente. Posteriormente transmitimos a las nuevas generaciones todo este bagaje cultural.

Desde elmomento del nacimiento, la sociedad asigna ala personaun género através del médico, la partera, la familia, amigos/as; basándose en la observación de los órganos sexuales externos. Esto modificarála vida futura de ese individuo, el cual recibirá por ello un trato diferencial según la asignación, sea masculina o femenina. La familia, la escuela, el entorno social, los medios de comunicación, serán los encargados de transmitir una serie de valores relacionados a esa diferenciación (ÁGORA, 2011).

Cada sociedad establece entonces un orden basado por lo general en la dicotomía de lo masculino y lo femenino; es sobre esta base genérica que cada grupo social elabora sus reglas y normas, así se va respondiendo a la manera de pensar, de ser y de sentir. La sociedad sexista es un claro ejemplo de ello. Existe una sociedad sexista que se ha expandido a todos los ámbitos de nuestra vida, una vida que es identificada por muchas personas como desigual.

La equidad de género significa tomar conciencia y transformar la posición de desigualdad y subordinación que las mujeres han vivenciado a través de siglos de historia en relación a los hombres en la esfera familiar, económica, social, política, cultural y en la misma historia, teniendo presente las circunstancias de clase social, edad, etnicidad, orientación sexual o identificación religiosa que pueden agravar o acentuar estas desigualdades. La equidad de género implica el estudio de las desigualdades entre los géneros, señalando las causas que las producen. Ahora bien, no se trata solo de constatar 
las desigualdades y discriminaciones en los grupos humanos, sino que debe actuarse en los distintos niveles para conseguir equidad e igualdad.

Según García, Jiménez y Martínez (2005), las estrategias más adecuadas para lograr la igualdad y equidad de género, es promover la igualdad de trato en todas las esferas sociales; se requiere además adoptar acciones positivas para hombres y para mujeres que permitan corregir las desigualdades; aplicar la perspectiva de género permitiendo integrar la igualdad en las estructuras, organizaciones, políticas y acciones; y dotar a las mujeres de un papel protagónico de sus propias vidas mediante el fortalecimiento en la participación de la toma de decisiones de todos los ámbitos de la vida social.

Históricamente se ha avanzado en la consecución de las metas para alcanzar la equidad de género, pero sigue sin existir plena igualdad de oportunidades entre hombres y mujeres prácticamente en todos los estados y sociedades. Conseguir la igualdad de condiciones y oportunidades requiere que las personas estén por encima de las diferencias y que el género no sea tomado como categoría diferencial para separar, excluir o violentar a ninguna persona. Lograr esta meta supone un largo proceso de cambio en las normas sociales, culturales, políticas y económicas de todas las sociedades, pero confiamos que en este camino nos encontramos.

\section{Referencias}

ÁGORA (2011). La construcción social de la identidad de género. Módulo I. Ciudad Autónoma de Ceuta. Consejería de Educación y Centro Asesor de la Mujer. Cultura y Mujer. España: Recuperado de http://www.ceuta.es/ceuta/images/servicios/mujer/documentos/documentos/ViolenciadeGenero.EfectosyRepercusiones.pdf

AGUIRRE, A. (2005). La ciudad de las damas de Cristina de Pizán. Obra primigenia del feminismo. México: UNAM Triple jornada.

ALBERTINI, P. (2008). Semblanza de Simonne de Beauvoir a 100 años de su nacimiento. Campus Montecillo. Recuperado de http://elmorsa.blogspot.com/20o8/o1/los-10o-aos-de-simone-debeauvoir.html

ÁLVAREZ R., S. (2007). Identidades y teoría de género. Hembra, mujer, femenina. Emprendedoras en la Red. Recuperado de http://www.emprendedorasenred.com.ar/noticias_detalle.php?id=492

AMORÓS, C. (1995). Feminismo y ética. Revista de filosofía moraly política. (6).

ARAYA, S. (2003). Relaciones sexistas en la educación. Revista de Educación (27).

BEAUVOIR, S. (1948-1949). El Segundo sexo. Los hechos y los mitos. Editorial Siglo Veinte. Recuperado de http://www.segobver.gob.mx/genero/docs/Biblioteca/El_segundo_sexo-_Simone_de_B.pdf 
BEBEL, A. (1879). La mujer y el socialismo. Jubileo 50 edición. Recuperado de http://www.marxists. org/archive/bebel/1879/woman-socialism/index.htm

BEBEL, A. (2004). Biografías y Vidas. Recuperado de http://www.biografiasyvidas.com/biografia/b/ bebel.htm

BELTRÁN S., J. (1994). La formación de la mujer cristiana. Traducción y notas, Biblioteca Valenciana.

BELTRÁN, J. (2003). Sobre género y educación. España: Tirant.

BID (2014). Promoviendo la igualdad de género para mejorar los resultados de desarrollo. Banco Interamericano de Desarrollo. Recuperado de https://publications.iadb.org/bitstream/handle/11319/6359/Promoviendo\%2ola\%2oigualdad\%2ode\%2ogenero.pdf?sequence=2

BISWAS, A. (2004). La tercera ola feminista: Cuando la diversidad, las particularidades y las diferencias son lo que cuenta. México, UAM. Revista de difusión de septiembre de 2004. Recuperado de http:// www.uam.mx/difusion/revista/sep2004/biswas.pdf

BLAZQUEZ G., N. (2011). El retorno de las brujas. Incorporación, aportacionesy críticas de las mujeres a la ciencia. Universidad Nacional Autónoma de México. Centro de Investigaciones Interdisciplinarias en Ciencias y Humanidades. Colección debate y reflexión. Recuperado de http://computo.ceiich. unam.mx/webceiich/docs/libro/El\%2oretorno\%2ode\%2olas\%2obrujas.pdf

BOIX, M. (2005). La educación de las niñas, una lucha histórica. Recuperado de http://www.educacionenvalores.org/spip.php?article186

BONAL, X. y TOMÉ, A. (1997). Construir la escuela coeducativa, la sensibilización del profesorado. Cuadernos para la Coeducación. España: Instituto de Ciencias de la Educación, Universidad Autónoma de Barcelona.

BONET, H. (2006). Les dones en la prehistoria. España: Museo de Valencia (Ed.).

BOURDIEU, P. (200oa). Existir para la mirada masculina: la mujer ejecutiva, la secretaria y su falda. Entrevista con Pierre Bourdieu. Tomado de la revista francesa Télérama. Julio-agosto, 1998. Traducción: Carlos Bonfil. Recuperado de http://www.jornada.unam.mx/200o/o5/o4/ls-bourdieu.html

BOURDIEU, P. (200ob). La dominación masculina. Traducido por Joaguín Jordá. España: Anagrama.

BURÍN, M. y Meler, I. (200o). Varones. Género y subjetividad masculina. Argentina: Paidós.

BUTLER, J. (1990). Gender trouble: Feminism and the subversion of identity, routledge. New York: Soft Cover Publisher.

BUTLER, J. (2001). El género en disputa: el feminismo y la subversión de la identidad. México: Paidós.

BUTLER, J. (2007). Construcción sexualy perfomatividad del género. Entrevista por Alejandra Barquero, 2013. Recuperado de http://www.suite101.net/content/judith-butler-construccion-sexual-y-performatividad-del-genero-a36297\#ixzz1LcZvHlYo 
CADY STANTON, E. (1848). Declaración de Séneca Falls. Traducción de Alicia Miyares. Recuperado de http://webs.uvigo.es/pmayobre/textos/varios/seneca_falls.pdf

CARLETTI, E. J. (2006). Estudian las relaciones entre hombres y mujeres prehistóricos. Noticias de Axxon. Recuperado de http://axxon.com.ar/not/158/c-1580o2o.htm

CASTANY, P. (2004). Reseña de El segundo sexo, de Simonne de Beauvoir. Recuperado de http:// www.eldigoras.com/eomo3/2004/2/tierra38bcpo8.htm

CAZÉS, M. D. (2007). Obras feministas de Francois Poulain de la Barre. En: García, M. (Col.) Estudio preliminar. México: Centro de Investigaciones Interdisciplinarias en Ciencias y Humanidades UNAM, $1647-1723$.

CEDAW (1979). Convención de las Naciones Unidas para la eliminación de todas las formas de discriminación contra la mujer. Recuperado de http://www.hchr.org.mx/documentos/CEDAW\%2O Final.pdf

CEPAL (2000). Objetivos de desarrollo del milenio en América Latina y el Caribe. Recuperado de http://www.eclac.org/mdg/

CEPAL (2009). Estadísticas sociales. Anuario estadístico de América Latina y el Caribe.

CEPAL (2010). Igualdad de género: participación, autonomía y empoderamiento de las mujeres del nuevo informe de las Naciones Unidas sobre la región: América Latina y el Caribe avanza hacia los Objetivos del Milenio. Capítulo V. Recuperado de http://www.cepal.org/oig/noticias/noticias/9/40069/2010_622_ODM_ESPANOL_CapV.pdf

CEPAL (2012). Cambio estructural para la igualdad: Una visión integrada del desarrollo. CEPAL, 34 Período de sesiones de la Comisión. San Salvador, 330 p.p.

CERVANTES P., E. I. (2006). La nueva masculinidad en la posmodernidad. 1er Encuentro Académico de la DES de Ciencias de la Salud. Universidad Michoacana de San Nicolás de Hidalgo. Recuperado de http://dieumsnh.qfb.umich.mx/masculinidad.htm

CHAZINE, J. M. y FAGE, L. H. (2009). Bornéo, La mémoire des grottes. Traducción al español: Borneo, La memoria de las cuevas. Ediciones de la FAGE.

CHIAROTTI, N. (1995). Primera Conferencia Mundial sobre la Mujer, México 1975. Recuperado de http://base.d-p-h.info/es/fiches/premierdph/fiche-premierdph-2359.html

CIJ (2007). Centros de integración juvenil. A.C. Secretaría de salud, México. Recuperado de http:// www.cij.gob.mx/Paginas/MenuIzquierdo/ConoceSobre/Genero/quegenero.asp

CIM (2001). Programa interamericano sobre la promoción de los derechos humanos de la mujer y la equidad e igualdad de género. Comisión interamericana de mujeres. Secretaría General de la Organización de los Estados Americanos. Recuperado de http://www.summit-americas.org/vp/ CIM/Programa_InterAmCIM_Cuatro_idiomas.pdf 
COMISIÓN INTERAMERICANA DE DERECHOS HUMANOS (2009). Convención interamericana para prevenir, sancionar y erradicar la violencia contra la mujer: Convención de Belém Do Pará, 1994. Recuperado de http://www.cidh.org/women/convencion.htm

CONSTITUCIÓN POLÍTICA DE LOS ESTADOS UNIDOS MEXICANOS (2009). Recuperado de http://www.cddhcu.gob.mx/LeyesBiblio/pdf/1.pdf

CURA, R. O. (2011). La filosofía educativa de Juan Luis Vives. Tesis de Licenciatura. Universidad Católica. Argentina: Facultad de Filosofía y Letras. Recuperado de http://bibliotecadigital.uca.edu. ar/repositorio/tesis/filosofia-educativa-juan-luis-vives.pdf

DE BARBIERI, T. (1992). Sobre la categoría de género: Una introducción teórico-metodológica. Chile: Isis Internacional.

DE MIGUEL, A. y Romero, R. (2003). Flora Tristán:feminismo y socialismo. Madrid, España: Los libros de la catarata.

ELJACH, S. (2011). Violencia escolar en América Latina y el Caribe superficie y fondo. UNICEF. Recuperado de http://www.unicef.org/lac/violencia_escolar_OK.pdf

ENGELS, F. (1884). El origen de la familia, la propiedad privada y el Estado. Traducida por la Editorial Progreso, Moscú, 4 a edición del libro. Recuperado de http://www.marxists.org/espanol/m-e/188os/ origen/el_origen_de_la_familia.pdf

ENGELS, F. y MARX, K. (1846). La ideología alemana. Libro digitalizado por Julio Rodríguez, 2011. Recuperado de http://www.marxists.org/espanol/m-e/1846/ideoalemana/index.htm

FLORES, A. (2004). El feminismo en la ciencia. Reflexiones feministas en ciencias. México: Cuadernos del CUEG.

FONTENLA, M. (2008). ¿Quées el patriarcado? Periódico feminista: Mujeres en la red. Artículo publicado en el Diccionario de estudios de género y feminismos; Editorial Biblos. Recuperado de http:// www.nodo5o.org/mujeresred/spip.php?article1396

FRANCO G., C. (2008). Pensamiento pedagógico de Juan Luis Vives. Una introducción. GIBRALFARO Revista Digital de Creación Literaria y Humanidades. 2 (56). Julio-Agosto de 2008. Recuperado de http://www.gibralfaro.uma.es/educacion/pag_1471.htm

FRAPPANT, J. C. (2008). La violencia contra las mujeres de la prehistoria a la sociedad occidental. Marzo 24, Atenea TV, Tu canal audiovisual. Recuperado de http://ateneatv.wordpress.com/2008/03/24/ la-violencia-contra-las-mujeres-de-la-prehistoria-a-la-sociedad-occidental/

FRIEDAN, B. (1981). La segunda fase. Estudios sobre feminismo y la condición de la mujer. España.

FRIEDAN, B. (200o). Entrevista a Betty Friedan por Isabel Martínez Lozano, Revista MeridIAM (17). España: Instituto Andaluz de la Mujer. Recuperado de http://www.nodo5o.org/mujeresred/betty_friedan.html 
GARCÍA, M.; JIMÉNEZ, L. y MARTÍNEZ, E. (2005). Políticas de investigación en salud, en Guía de recomendaciones para la incorporación de la perspectiva de género. Observatorio de Salud de la Mujer. Dirección General de la Agencia de Calidad del Sistema Nacional de Salud. Secretaría General de Sanidad. Ministerio de Sanidad y Consumo. Recuperado de http://www.msssi.gob. es/organizacion/sns/planCalidadSNS/pdf/equidad/PROPUESTA_DE_GUIA_NIVEL_POLITICAS_DE_INVESTIGACION_EN_SALUD.pdf

GOETZ, A. M. (2007). Justicia de género, ciudadanía y derechos. Conceptos fundamentales, debates centrales y nuevas direcciones para la investigación. Centro Internacional de Investigaciones para el Desarrollo, la Justicia de género y la Ciudadanía. Editado por Maitrayee Mukhopadhyay y Navsharan Singh. Mayol Ediciones/IDRC 2008. ISBN 978-958-8307-21-3.290 p.p. Recuperado de http://www.idrc. ca/agua/ev-111764-201-1-DO_TOPIC.html\#cho2fn1

GONZÁLEZ P., C. (2005). Christine de Pizan (1364-1430). Escritoras y pensadoras europeas. Ministerio de Educación y Ciencia. Recuperado de http://www.escritorasypensadoras.com/downloadpdf. $\mathrm{php} / 25$

GRANADOS, V. (2006). Breve historia del feminismo. México: Recuperado de http://sepiensa.org.mx/ contenidos/2006/hist_femini/hist_femini_1.htm

HOFF, C. S. (1994). ¿Quién se robó el feminismo? Estados Unidos: Alfaguara

HOFF, C. S. (2006). La guerra contra los chicos. Cómo un feminismo mal entendido está dañando a los chicos jóvenes. RIS, 65 (47), 221-240.

HUMAN RIGHTS WATCH (2001). Reporte del mundo para el 2001. Recuperado de http://www.hrw. org/legacy/wr2k1/

IBARRA, E. (2011). A 154 años de su nacimiento. Clara Zetkin. Organización Aporrea. Recuperado de www.aporrea.org/ideologia/a126221.html

INMUJERES N. L. (2007). La violencia de género en el ámbito escolar. Manual de instrucción. México: Instituto Estatal de las Mujeres de Nuevo León.

INMUJERES N. L. (2009). Gobierno del Estado de Nuevo León. Administración 2003-2009. Recuperado de http://www.nl.gob.mx/

INTERNATIONAL WOMENS HEALTH (2008). Declaración y Plataforma de Acción de Beijing, China, 1995. Recuperado de http://www.iwhc.org/index.php?option=com_content\&task=view\&i$\mathrm{d}=318$ o\&Itemid $=254$

JAGGAR, A. (1999). Feminism in philosophy, Feminism in ethics: Moral justification, Cambridge, Cambridge University Press.

KNAPP, P.y VON ZELL, M. (2007). Mujery trabajo en la Edad Media. Recuperado de http://sandradodd. com/sca/womenandwork

LAGARDE, M. (1997). Género y feminismo. Desarrollo humano y democracia. Madrid: Horas y horas. 
LAGARDE, M. (2004). Identidad femenina. México: UNAM.

LAMAS, M. (2007). Equidad de género en la UNAM. Recuperado de http://www.pueg.unam.mx/documentos/Foro_equidad/Equidad_Marta_Lamas.pdf

LANDERO, R. (2003). Familia, poder, violenciay género. México: Universidad Autónoma de Nuevo León.

LIGHT, D.; KELLER, S. y CALHOUN, C. (1991). Sociología. Colombia: McGraw Hill.

LÓPEZ M., J. J. (2006). El código civil de Napoleón y los derechos humanos. Revista de derecho privado, nueva época, V (13-14), 81-91. Recuperado de http://www.juridicas.unam.mx/publica/librev/rev/ derpriv/cont/13/dtr/dtr5.pdf

MARCHESI, A. (2000). ¿Equidad en la educación? Un sistema de indicadores de desigualdad educativa. Revista Iberoamericana de Educación (23).

MARTÍNEZ P., C. (2003). El papel de la mujer en la evolución humana. España: Biblioteca Nueva.

MICHEL, A. (2001). Los estereotipos sexistas en la escuela y en los manuales escolares. Educere Universidad de los Andes, Mérida. 5 (12), 67-77.

MONTAÑO, S. (2007). Estadisticas para la equidad de género. Magnitudes y tendencias para América Latina. Unidad Mujer y Desarrollo. México: CEPAL.

MUKHOPADHYAY, M. y SINGH, N. (2007). Justicia de género, ciudadanía y desarrollo. Centro Internacional de Investigaciones para el Desarrollo (IDRC). Recuperado de http://generomexico. colmex.mx/textos/JusticadeGeneroCiudadniayDesarrollo-o8.pdf

NASH, M. (2004). Mujeres en el mundo. Historia, retos y movimientos. Madrid: Alianza Editorial.

NAVARRO, R. (2004). Mujeres mexicanas que sufren y aman demasiado. México: Pax.

O'LEARY, D. (1998). La ideología de género, sus peligros y alcances. Comisión ad-hoc de la mujer. Perú: Comisión Episcopal de Apostolado Laica.

OMS (2006). Estadísticas de la Organización Mundial de la Salud. Recuperado de http://www.cema. edu.ar/publicaciones/download/documentos/126.pdf

ONU (1948). Declaración universal de los derechos humanos. Recuperado de http://www.un.org/es/ documents/udhr/index.shtml\#a26

ONU (1989). Convención sobre los derechos del niño. Recuperado de http://www.cimacnoticias.com/ especiales/amndi/instrumentos_inter/1_convencion_derechos_nino.pdf

ONU (1990). Octavo congreso sobre la prevención del delito y el tratamiento del delincuente que practica la violencia contra la mujer. Recuperado de http://www.uncjin.org/Documents/congr1o/15s.pdf

ONU (1993). Conferencia mundial sobre los derechos humanos, Viena. Recuperado de http://www. unic.org.ar/prensa\%2ohojasinfo/archivos/11congeso-afiches3.pdf 
ONU (1995). Cuarta conferencia mundial de la mujer, China, 1995. Recuperado de http://www.un.org/ spanish/conferences/mujer.htm

ONU (1995). Cumbre Mundial de Desarrollo, Copenhague. Recuperado de http://www.un.org/spanish/esa/socdev/

ONU (2000). Declaración del Milenio. Recuperado de http://www.un.org/spanish/milenio/ares552.pdf

ONU (2005). Sobre la mujer, igualdad, desarrollo y paz en Naibori, 1985. Recuperado de http://www. un.org/es/development/devagenda/gender.shtml

ONU (2006). La violencia contra niños, niñas y adolescentes. Informe de América Latina en el marco del estudio mundial de las naciones unidas. Secretaría regional de la organización de naciones unidas. Master Litho S.A

ONU (2009). Declaración universal de derechos humanos de 1948. Recuperado de http://www.un.org/ es/documents/udhr/

ONU (2012). Estado de las ciudades del mundo 2012/13: La prosperidad de las ciudades.

PAES, R.;FERREIRA, F.; MOLINAS, J.y SAAVEDRA, J. (2008). Midiendo la desigualdad de oportunidades en América Latina y el Caribe. Banco Mundial. Edición de Conferencia: octubre 2008.

PEÑA, M. (1997). La agenda del siglo XXI: Hacia un desarrollo humano. Programa de naciones unidas para el desarrollo. Recuperado de http://www.ing.unal.edu.co/admfac/iei/comunicados/docs/ educacion_agenda_siglo_XXI.pdf

PINTOS DE C. N., M. (2007). Religiones monoteistas y teología feminista. España: ADIM. Recuperado de http://nevada.ual.es:81/cursosdeotonno/ponencias/RELIGIONES_MONOTEISTAS_Y_TEOLOGIA_FEMINISTA.pdf

PLAN NACIONAL DE DESARROLLO (2008). Plan nacional de desarrollo 2007-2012. Mensaje del presidente Felipe Calderón Hinojosa. Recuperado de http://pnd.presidencia.gob.mx/

PNUD (1995). Informe sobre desarrollo humano 1995: La revolución hacia la igualdad en la condición de los sexos. Recuperado http://hdr.undp.org/es/informes/mundial/idh1995/capitulos/espanol/

PNUD (2005). Informe sobre desarrollo humano. Cooperación internacional ante una encrucijada, ayuda al desarrollo. Comercio y seguridad en un mundo desigual. PNUD, Ediciones Mundi-Prensa. Recuperado de http://es.scribd.com/doc/131713794/Informe-Sobre-Desarrollo-Humano

POULAIN, F. (1673). De la educación de las damas. España: Cátedra.

PROVEYER C., C. (2005). Selección de lecturas de sociología y política social de género. Cuba: Félix Varela.

PULEO, A. (200o): Filosofía, género y pensamiento crítico. España: Universidad de Valladolid.

PUlEO, A. H.; CONDORCET, J.; DE GOUGES, O. y DE MARGUENAT, A. (1993). La ilustración olvidada: la polémica de los sexos en el siglo XVIII. México: Anthropos. 
RAYA, R. (2012). ¿Cuánto mide la desigualdad de género en tu país? Índice de Inequidad de Género. Social Whath. Philippines: ITEM. Recuperado de http://www.socialwatch.org/es/node/14380

REHERMANN, C. (2012). Cantos a la Dama Amor: Místicas y trovadoras de la Edad Media. Artículos, ensayos y otros textos. Recuperado de http://www.henciclopedia.org.uy/autores/Rehermann/ Literaturafemenina.htm

REL-UITA (30 de junio de 2006). "La prehistoria fue más igualitaria”. Diario El País.es. España Recuperado de http://www.rel-uita.org/mujer/prehistoria_igualitaria.htm

RODRÍGUEZ P.; REY, J. y TRIMIÑO, C. (2007). La lucha por los derechos de las mujeres en el siglo XIX. Escenarios, teorías, movimientos y acciones relevantes en el ámbito angloamericano. 3 (2), 1153-1220.

ROUSSEAU, J. J. (1762). El Emilio o de la educación. Traducción de Ricardo Viñas. Recuperado de http:// escritoriodocentes.educ.ar/datos/recursos/libros/emilio.pdf

SÁNCHEZ R., M. (28 de junio de 2007). El lugar de la mujer en la prehistoria. Entrevista realizada por el Periódico Mundo Neandertal. Recuperado de http://neanderthalis.blogspot.com/2007/o6/ellugar-de-la-mujer-en-la-prehistoria.html

SANTA-CRUZ, M. I. (1994). Aportes para una crítica de la teoría de género. En: Mujeres y filosofía. Teoría filosófica de género, (Comp.), CEAL.

SANTOS, G., M. (2008). Desde la discriminación hacia la justicia: El camino de la coeducación. Ramos, J. (coord.). El camino hacia una escuela coeducativa. España: Movimiento cooperativo de la escuela popular. 17-30.

SCOTT, J. W. (1986). Gender, a useful category of historical analysis, American Historical Review, 91. Chicago, p. 1053-1075.

SEABRA DE ALMEIDA R. A. (2009). La Identidad de Género en la Edad Media, una cuestión polémica, conferencia ofrecida el 3 de Julio de 2009 en el XIV Curso de Estudios de la Cátedra de Estudios Medievales del Comtat d'Urgell, realizado en Balaguer (España).

SEP (2009). Informe nacional sobre violencia de género en la educación básica en México. Secretaría de Educación Pública de México (SEP) y Fondo de las Naciones Unidas para la Infancia (UNICEF). 1ra. edición. ISBN: 978-607-95351-1-7. Recuperado de http://www.sep.gob.mx/work/appsite/ basica/informe_violenciak.pdf

SEP (2010). Primera encuesta nacional exclusión, tolerancia y violencia en escuelas públicas en México. Secretaría de Educación Pública de México.

SOLER, B. (2011). La prehistoria no es solo cosa de hombres. El diario montañés. Recuperado de http://www. eldiariomontanes.es/v/20110114/cultura/sotileza/prehistoria-solo-cosa-hombres-20110114.html 
SOLER, B. y Alcántara, J. (2006). Las mujeres en la prehistoria, guía didáctica. Museo de prehistoria de Valencia. Recuperado http://www.museuprehistoriavalencia.es/resources/files/Didactica/ Guia_Dones_Castellano.pdf

STOLLER, R. (1968). Sex and gender. New York: Science House.

STUART M., J. (1869). La esclavitud femenina. Recuperado de http://www.kclibertaria.comyr.com/ lpdf/l109.pdf

STUART M., J. (2004). El utilitarismo. Primera edición cibernética, mayo de 2004. Recuperado de http://www.antorcha.net/biblioteca_virtual/filosofia/utilitarismo/indice.html

STUURMAN, S. (2004). François Poulain de la Barre and the invention of modern equality. Cambridge, Mass. : Harvard University Press.

TAYLOR M., H. (1851). La liberación de las mujeres. Traducción de Elena Gallego Abaroa, 2005. Mujeres economistas 1816-1898, Madrid: Delta.

TEDESCHI C., S. (2013). La mística de la feminidad. Blog de coaching evolutivo. Recuperado de https:// suevolucion.wordpress.com/2013/o3/11/la-mistica-de-la-feminidad/

TRISTÁN, F. (2003). Pionera, revolucionaria y aventurera del siglo XIX. México: Maeva.

UNESCO (2000). Marco de acción de Dakar. Foro Mundial sobre la Educación: Educación para Todos, cumplir nuestros compromisos comunes. (Senegal, 26-28 de abril de 200o).

UNESCO (2005). La educación como derecho humano. Textos de Marta Urrutxi. Graficolor.

UNESCO (2010). Llegar a los marginados. Resumen del informe y panorámica regional: América Latina y el Caribe. Informe de seguimiento de la educación para todos en el Mundo.

UNESCO (2015). Informe de Seguimiento de la Educación para Todos en el Mundo 2000-2015: Logros y Desafíos. Recuperado de http://unesdoc.unesco.org/images/oo23/oo2324/232435s.pdf

UNICEF (2007). Todas las niñas y los niños, en todas partes. Una estrategia en favor de la educación básica y la igualdad entre los géneros. Estrategia educativa de UNICEF. Recuperado de www.unicef.org/ about/execboard/files/o7-10_education_strategy.pdf

UNICEF (2009). Estado mundial de la infancia. Edición especial, Conmemoración de los 20 años de la Convención sobre los derechos del niño, noviembre de 2009. Brodock Press.

URRUZOLA, M. (2003). Prevención de la violencia sexista desde la escuela. España: Horas y horas.

VALCÁRCEL, A. (1991). Sexo y filosofia. Barcelona: Anthropos.

VÁSQUEZ, M. G. (2004). Algunas reflexiones sobre Cristina de Pizán y su obra: La ciudad de las damas. Recuperado de http://agendadelasmujeres.com.ar/pdf/reflexiones_cristina_de_pizan.pdf

VIVES, J. L. (1523). Instrucción de la mujer cristiana. Traducción de Juan Justiniano en 1793, España: Imprenta de Don Benito Cano. 
WEBER, M. (1905). La ética protestante y el espíritu del capitalismo. Recuperado de http://www. biografiasyvidas.com/biografia/w/weber_max.htm

WOLLSTONECRAFT, M. (1791). Vindicación de los derechos de la mujer. Recuperado de http://64.233.167.104/search?q=cache:aodui_rvc4MJ:www.educastur.princast.es/cpr/aviles/asesorias/socioling/WOLLSTONECRAFT.doc+Wollstonecraft,+Mary.+(1791)+Vindicaci\%C3\%B$3 \mathrm{n}+\mathrm{de}+\mathrm{los}+$ derechos + de $+\mathrm{la}+$ mujer. $\& \mathrm{hl}=\mathrm{es} \& \mathrm{ct}=\mathrm{clnk} \& \mathrm{~cd}=4 \& \mathrm{gl}=\mathrm{mx} \& \mathrm{client}=$ firefox $-\mathrm{a}$

ZEMON D., N. (1976). Women's history in transition: the European case. Feminist Studies, 3 Maryland, 90. 


\section{Anexos} \begin{tabular}{l|l} 
TABLA 1 & $\begin{array}{l}\text { Legislaciones, tratados y convenios internacionales en materia de equidad } \\
\text { de género }\end{array}$
\end{tabular}

\begin{tabular}{|c|c|}
$\begin{array}{c}\text { Fecha } \\
\text { y lugar }\end{array}$ & $\begin{array}{c}\text { Nombre del instru- } \\
\text { mento y organismo }\end{array}$ \\
\hline 1848 & $\begin{array}{c}\text { Declaración de } \\
\text { Seneca Falls }\end{array}$ \\
\hline Nueva York & $\begin{array}{c}\text { 1ra Asamblea en } \\
\text { Defensa de los Dere- } \\
\text { chos de la Mujer }\end{array}$ \\
\hline
\end{tabular}

En qué consistió y qué estableció

en materia de equidad de género

26 de junio de

1945

San Francisco

EEUU

\section{Carta de las Na-} ciones Unidas. ONU

Basada en la declaración de independencia de los EEUU. Denuncia las restricciones políticas a que estaban sometidas las mujeres, entre ellas: no poder votar, ni presentarse a elecciones, no ocupar cargos públicos, ni afiliarse a organizaciones políticas o asistir a reuniones políticas. Destaca en su tercer punto: "que la mujer es igual al hombre (que así lo pretendió el Creador) y que por el bien de la raza humana exige que sea reconocida como tal".

Reafirma la fe en los derechos fundamentales del hombre y la mujer, en su dignidad como personas y en igualdad de derechos en todas las naciones. Consta de 14 capítulos que establecen disposiciones que los Estados partes deben realizar para cumplir con el objetivo de crear condiciones bajo los cuales puedan mantenerse la justicia y el respeto, así como promover el progreso social dentro de un concepto amplio de libertad y tolerancia.

$\begin{array}{cc}\begin{array}{c}\text { 10 de diciembre } \\ \text { de } 1948\end{array} & \begin{array}{c}\text { Declaración Uni- } \\ \text { versal de los Dere- } \\ \text { chos Humanos. }\end{array} \\ \text { Nueva York } & \text { ONU } \\ \text { EEUU } & \end{array}$

Conformada por 30 artículos, en los cuales se consideró que la libertad, la justicia y la paz en el mundo tienen por base el reconocimiento de la dignidad intrínseca y de los derechos iguales e inalienables de todos los miembros de la familia. Sus artículos 1 y 2 destacan que: "Todos los seres humanos nacen libres e iguales en dignidad y derechos y dotados como están de razón y conciencia, deben comportarse fraternalmente los unos con los otros. Toda persona tiene los derechos y libertades sin distinción alguna de raza, color, sexo, idioma, religión, opinión política o de cualquier otra índole, origen nacional o social, posición económica, nacimiento o cualquier otra condición".

$\begin{array}{cc}\begin{array}{c}\text { 20 de diciembre } \\ \text { de } 1952\end{array} & \begin{array}{c}\text { Convención sobre } \\ \text { los derechos políti- } \\ \text { cos de la mujer. }\end{array} \\ \text { EEUU } & \text { ONU }\end{array}$

Posee 11 artículos que determinan poner en práctica el principio de la igualdad de derechos de hombres y mujeres enunciando en la Carta de Naciones Unidas. Reconoce que toda persona tiene derecho a participar en el gobierno de su país directa y libremente, a iguales oportunidades de ingreso en el servicio público de su país, a iguales condiciones entre el hombre y la mujer en el disfrute y ejercicio de los derechos políticos, conforme a las disposiciones de la Carta de la ONU y de la Declaración Universal de Derechos Humanos. El art. 1 destaca que "las mujeres tendrán derecho a votar en todas las elecciones en igualdad de condiciones con los hombres, sin discriminación alguna". 
7 de noviembre de 1967

EEUU
Declaración sobre la eliminación de la discriminación contra la mujer. ONU
Consta de 11 artículos que expresan que la discriminación contra la mujer es incompatible con la dignidad humana, con el bienestar de la familia y de la sociedad; que esta impide la participación en la vida política, social, económica, cultural de los países y constituye un obstáculo para el pleno desarrollo de las posibilidades que tienen las mujeres de servir a sus países y a la humanidad. Manifiesta que se debe promover la igualdad entre el hombre y la mujer. Los Estados deberán adoptar medidas apropiadas para abolir las leyes, costumbres, reglamentos y prácticas que constituyan discriminación en contra de la mujer y asegurar la protección jurídica adecuada de la igualdad de derechos entre ambos sexos. El artículo 1 destaca que "la discriminación contra la mujer, por cuanto niega o limita su igualdad de derechos con el hombre, es fundamentalmente injusta y constituye una ofensa a la dignidad humana".

$\begin{array}{cc}\text { 19 de junio al } 2 & \begin{array}{c}\text { Primera Conferen- } \\ \text { de julio de } 1975 \\ \text { cia Mundial sobre } \\ \text { México }\end{array} \\ \text { la Mujer }\end{array}$

Se habló sobre igualdad, desarrollo y paz. Se emitieron dos importantes documentos: La declaración de México sobre la igualdad de la mujer y su contribución al desarrollo y la paz, y el plan de acción mundial para la instrumentación de los objetivos del año internacional de la mujer. Se ratificó e institucionalizó el año internacional de la mujer.

$\begin{array}{cc}\text { 18 de diciembre } & \text { Convención sobre } \\ \text { de } 1979 & \begin{array}{c}\text { la eliminación de } \\ \text { todas las formas } \\ \text { Nueva York }\end{array} \\ \text { EEUU } & \begin{array}{c}\text { discriminación } \\ \text { contra la mujer } \\ \text { CEDAW, ONU }\end{array}\end{array}$

Primer tratado internacional que reconoce expresamente los derechos humanos de las mujeres. Consta de 30 artículos en los que se define el significado de discriminación contra la mujer e igualdad entre los sexos; dice cómo lograr esta igualdad. Propone la creación de un comité para asegurar que estas medidas se realicen. Reconoce que las mujeres siguen siendo objeto de discriminaciones y ésta acción viola los principios de igualdad de derechos y del respeto a la dignidad humana. Los artículos 4 y 15 detallan que "los Estados adoptarán medidas especiales para acelerar la igualdad entre el hombre y la mujer, además que ambos tienen los mismos derechos ante la ley".

$\begin{array}{cc}7 \text { de noviembre } & \text { Declaración sobre } \\ \text { de } 1967 & \begin{array}{c}\text { la eliminación de } \\ \text { la discriminación } \\ \text { EEUU }\end{array} \\ & \text { ONU la mujer. }\end{array}$

Consta de 11 artículos que expresan que la discriminación contra la mujer es incompatible con la dignidad humana, con el bienestar de la familia y de la sociedad; que esta impide la participación en la vida política, social, económica, cultural de los países y constituye un obstáculo para el pleno desarrollo de las posibilidades que tienen las mujeres de servir a sus países y a la humanidad. Manifiesta que se debe promover la igualdad entre el hombre y la mujer. Los Estados deberán adoptar medidas apropiadas para abolir las leyes, costumbres, reglamentos y prácticas que constituyan discriminación en contra de la mujer y asegurar la protección jurídica adecuada de la igualdad de derechos entre ambos sexos. El artículo 1 destaca que "la discriminación contra la mujer, por cuanto niega o limita su igualdad de derechos con el hombre, es fundamentalmente injusta y constituye una ofensa a la dignidad humana".

Se habló sobre igualdad, desarrollo y paz. Se emitieron dos importantes documentos: La declaración de México sobre la igualdad de la mujer y su contribución al desarrollo y la paz, y el plan de acción mundial para la instrumentación de los objetivos del año internacional de la mujer. Se ratificó e institucionalizó el año internacional de la mujer. 


$\begin{array}{cc}\text { 18 de diciembre } & \begin{array}{c}\text { Convención sobre } \\ \text { de } 1979\end{array} \\ \text { Nueva York } & \begin{array}{c}\text { eliminación de } \\ \text { todas las formas } \\ \text { de discriminación } \\ \text { contra la mujer, } \\ \text { EEUU }\end{array} \\ & \text { CEDAW, ONU }\end{array}$

\begin{tabular}{|c|c|}
\hline $\begin{array}{c}14 \text { al } 29 \text { de junio } \\
\text { de } 1980\end{array}$ & $\begin{array}{l}\text { Segunda Confe- } \\
\text { rencia Mundial de }\end{array}$ \\
\hline Copenha-gue & $\begin{array}{l}\text { la Mujer. } \\
\text { ONU }\end{array}$ \\
\hline
\end{tabular}

14 al 26 de julio

de 1985

Nairobi

Kenia

Tercera Conferen-
cia Mundial de la
Mujer, Igualdad,
Desarrollo y Paz.
ONU

Primer tratado internacional que reconoce expresamente los derechos humanos de las mujeres. Consta de 30 artículos en los que se define el significado de discriminación contra la mujer e igualdad entre los sexos; dice cómo lograr esta igualdad. Propone la creación de un comité para asegurar que estas medidas se realicen. Reconoce que las mujeres siguen siendo objeto de discriminaciones y ésta acción viola los principios de igualdad de derechos y del respeto a la dignidad humana. Los artículos 4 y 15 detallan que "los Estados adoptarán medidas especiales para acelerar la igualdad entre el hombre y la mujer, además que ambos tienen los mismos derechos ante la ley".

Se evaluaron los progresos logrados a partir de la primera conferencia. Se agregaron los subtemas de igualdad en el acceso a la educación, oportunidades de empleo y servicios adecuados de salud; se trataron asuntos sobre la libertad sexual femenina, la retribución al trabajo doméstico, etc. Se interpretó la igualdad no sólo en el sentido de igualdad jurídica, sino también de igualdad de derechos, responsabilidades y oportunidades para la participación de las mujeres en el desarrollo, como beneficiarias y como agentes activos. Se habló de violencia doméstica, que éste es un problema serio y complejo, que constituye una ofensa intolerable a la dignidad de los seres humanos.

Se evaluaron los avances y obstáculos presentados durante el Decenio de las Naciones Unidas para la Mujer (1975-1985), con los mismos temas abordados en la anterior: Igualdad, desarrollo y paz, educación, empleo y salud; además se habló sobre: leyes y desarrollo, servicios sociales, la industria, derechos de las lesbianas, comunicaciones, asuntos de investigación, medio ambiente y mujeres en artes y música. Se aprobó el documento: Buscar estrategias para la promoción de las mujeres para el año 200o. Las estrategias sirvieron de marco para la adopción de medidas en los planos nacional, regional e internacional, encaminadas a promover el reconocimiento social de la mujer, el ejercicio de sus derechos humanos y lograr la igualdad a escala nacional. Se reconoció que la igualdad, lejos de ser una cuestión aislada, abarca toda la esfera de la actividad humana. Se habló sobre violencia, pero en este caso se dijo que ésta es un obstáculo para el desarrollo de los países y para el logro de la paz.

14 al 25 de junio Conferencia Munde 1993 dial sobre los DeViena rechos Humanos.

Austria Declaración y Programa de Acción de Viena. ONU
La declaración sobre la eliminación de la violencia contra la mujer surge de esta conferencia, es considerado el primer instrumento internacional que atiende el problema de la violencia de manera específica. En sus 100 artículos se presenta un plan común para fortalecer la labor en pro de los derechos humanos en todo el mundo; se afirmaron los derechos de educación, capacitación e información pública, elementos esenciales para promover relaciones estables y armoniosas en las sociedades. Se declaró que los derechos de las mujeres constituían derechos humanos. Quedó rechazado el razonamiento que decía que los derechos humanos no se aplican a esferas privadas, como la vida en familia o las prácticas tradicionales o religiosas. 


\begin{tabular}{|c|c|c|}
\hline $\begin{array}{l}\text { Junio de } \\
1994 \\
\text { Brasil }\end{array}$ & $\begin{array}{c}\text { Convención Inte- } \\
\text { ramericana para } \\
\text { Prevenir, Sancio- } \\
\text { nar y Erradicar la } \\
\text { Violencia Contra } \\
\text { la Mujer. } \\
\text { OEA }\end{array}$ & $\begin{array}{l}\text { Llamada Convención Belem Do Pará, consta de } 25 \text { artículos } \\
\text { para prevenir, sancionar y erradicar la violencia contra la mu- } \\
\text { jer; define este concepto como cualquier acción o conducta, } \\
\text { basada en su género, que cause muerte, daño o sufrimiento } \\
\text { físico, sexual o psicológico a la mujer, tanto en el ámbito pú- } \\
\text { blico como en el privado. Esta convención propuso políticas } \\
\text { públicas específicas en ejes de acción que atendieran temas de } \\
\text { pobreza, violencia, salud, participación política, educación, } \\
\text { las niñas, los derechos humanos, el trabajo femenino, los me- } \\
\text { dios de comunicación y el medio ambiente. }\end{array}$ \\
\hline $\begin{array}{c}5 \text { al } 13 \text { de } \\
\text { septiembre de } \\
1994 \\
\text { El Cairo, } \\
\text { Egipto }\end{array}$ & $\begin{array}{c}\text { Conferencia Inter- } \\
\text { nacional de Pobla- } \\
\text { ción y Desarrollo. } \\
\text { ONU }\end{array}$ & $\begin{array}{l}\text { Se aprueba un programa de acción a } 20 \text { años que vincula la po- } \\
\text { blación, el desarrollo y el fomento de la autonomía de la mujer } \\
\text { y de los hombres. Se suscribieron compromisos cruciales para } \\
\text { convalidar un nuevo enfoque basado en el bienestar y los de- } \\
\text { rechos del individuo. Se propuso eliminar todas las formas dis- } \\
\text { criminatorias contra las mujeres, entre ellas la violencia; esto } \\
\text { ayudándolas a establecer y realizar sus derechos, incluidos los } \\
\text { relativos a la salud sexual y reproductiva. Se recomendó a los } \\
\text { países hacer mayores esfuerzos por promulgar, reglamentar y } \\
\text { hacer cumplir las leyes nacionales y las convenciones interna- } \\
\text { cionales en que sean partes. En el capítulo } 4 \text { se estableció la } \\
\text { necesidad de lograr la igualdad y la equidad entre el hombre } \\
\text { y la mujer.... }\end{array}$ \\
\hline $\begin{array}{c}4 \text { a } 15 \text { de } \\
\text { septiembre de } \\
1995 \\
\text { Beijing, China }\end{array}$ & $\begin{array}{l}\text { IV Conferencia } \\
\text { Mundial sobre la } \\
\text { Mujer: Acción para } \\
\text { la igualdad, el de- } \\
\text { sarrollo y la paz. } \\
\text { Declaración de } \\
\text { Pekín, conocida } \\
\text { como } \\
\text { Declaración y } \\
\text { Plataforma de } \\
\text { Acción Mundial de } \\
\text { Beijing. } \\
\text { ONU }\end{array}$ & $\begin{array}{l}\text { Se abre un nuevo capítulo en la lucha por la igualdad entre los } \\
\text { sexos, ya que traslada el foco de atención de las mujeres, al } \\
\text { concepto de género, reconociendo que toda la estructura de la } \\
\text { sociedad y las relaciones entre hombres y mujeres en el inte- } \\
\text { rior de esa estructura tenían que ser reevaluadas. Consta de } \\
361 \text { puntos generales y específicos. Se caracterizó el contexto } \\
\text { mundial, se establecen las esferas de especial preocupación y } \\
\text { se propusieron objetivos estratégicos que giraron en torno a la } \\
\text { mujer y la pobreza, educación y capacitación de la mujer, sa- } \\
\text { lud, violencia, los conflictos armados, la economía, el ejercicio } \\
\text { del poder y la adopción de decisiones, mecanismos institucio- } \\
\text { nales para el adelanto de la mujer, los derechos humanos, los } \\
\text { medios de difusión, el medio ambiente, la niña. Se plantearon } \\
\text { disposiciones institucionales y financieras en el plano nacio- } \\
\text { nal, subregional y regional e internacional. Se declaró que "la } \\
\text { violencia es un asunto de salud pública y se estableció que ésta } \\
\text { exige una acción urgente, con espíritu decidido, esperanza, } \\
\text { cooperación y solidaridad en los albores del nuevo siglo". }\end{array}$ \\
\hline $\begin{array}{l}25 \text { de junio } \\
\text { de } 2000 \\
\text { Nueva York } \\
\text { EEUU }\end{array}$ & $\begin{array}{c}\text { Beijing + } 5 \\
\text { La Mujer en el año } \\
\text { 20oo: igualdad } \\
\text { entre los géneros, } \\
\text { desarrollo y paz en } \\
\text { el siglo XXI. } \\
\text { ONU }\end{array}$ & $\begin{array}{l}\text { Se examinó el progreso alcanzado en los cinco años transcu- } \\
\text { rridos desde la aprobación de la Plataforma de Acción de Bei- } \\
\text { jing. Se reconoció la necesidad de participación igualitaria de } \\
\text { las mujeres en la toma de decisiones sobre macroeconomía; } \\
\text { los impactos negativos de la globalización en las mujeres y la } \\
\text { propuesta de asegurar un acceso igualitario a la protección so- } \\
\text { cial; el derecho a la herencia y la propiedad; la adopción del } \\
\text { protocolo facultativo de la convención sobre la eliminación de } \\
\text { todas las formas de discriminación contra la mujer; la inclu- } \\
\text { sión en el Estatuto de Roma de la Corte Penal Internacional de } \\
\text { todas las formas de violencia sexual como crímenes de guerra, } \\
\text { genocidio; y la necesidad que los gobiernos formulen nuevos } \\
\text { compromisos en relación con su responsabilidad en casos par- } \\
\text { ticulares, como los crímenes cometidos en nombre del honor y } \\
\text { los abusos cometidos por agentes no estatales. }\end{array}$ \\
\hline
\end{tabular}


5 al 8 de septiembre de 2000

Nueva York EEUU

\section{Cumbre del} Milenio. Declaración del Milenio. ONU
El documento: La función de las Naciones Unidas en el siglo XXI reafirmó la fe en la ONU y en su Carta, como cimientos indispensables para el establecimiento de un mundo más pacífico, próspero y más justo. Se describieron seis valores fundamentales que son esenciales para las relaciones internacionales en el siglo XXI: libertad, igualdad, solidaridad, tolerancia, respeto a la naturaleza y la responsabilidad común. En sus 32 puntos se habló sobre la paz, seguridad y el desarme; el desarrollo y la erradicación de la pobreza; la protección de nuestro entorno; los derechos humanos, democracia y buen gobierno; la protección a las personas vulnerables; la atención a las necesidades especiales de África y finalmente sobre el fortalecimiento de las Naciones Unidas. El punto 20 señala que se debe: "Promover la igualdad entre los sexos y la autonomía de la mujer como medios eficaces de combatir la pobreza, el hambre y las enfermedades y de estimular un desarrollo verdaderamente sostenible".

$\begin{array}{cc}\text { 31 de agosto a } 8 & \begin{array}{c}\text { Conferencia } \\ \text { de septiembre de } \\ \text { mundial contra el } \\ \text { racismo, la discri- } \\ \text { minación racial, } \\ \text { Sudáfrica }\end{array} \\ \begin{array}{c}\text { la xenofobia y las } \\ \text { formas conexas de } \\ \text { intolerancia. }\end{array} \\ & \text { ONU }\end{array}$

Consta de 122 puntos en los cuales se exige la rápida y completa eliminación de todas las formas de racismo, discriminación, xenofobia y formas conexas de intolerancia. Se instó a los Estados a encarar la discriminación basada en la raza y el género al planificar e implementar políticas, a revisar los mecanismos nacionales legales pertinentes con los que mujeres y hombres pueden obtener protección contra la discriminación basada en la raza y el género. Declara en el punto 7: "todos los seres humanos nacen libres e iguales en dignidad y derechos y están dotados de la posibilidad de contribuir constructivamente al desarrollo y al bienestar de sus sociedades. En el punto 62 destaca que: "somos conscientes que la historia de la humanidad está repleta de terribles injusticias infligidas por la falta de respeto a la igualdad de los seres humanos"

$\begin{array}{cc}\text { Marzo } & \text { Reunión Mujeres } \\ 2002 & \text { Líderes y } \\ \text { Finlandia } & \text { Ambiente. } \\ & \text { CMLM, la UICN } \\ & \text { y el Ministerio } \\ & \text { del Ambiente de } \\ & \text { Finlandia }\end{array}$

Se estableció una posición común para la Cumbre Mundial sobre el Desarrollo Sostenible (Johannesburgo, septiembre 2002) en torno a grandes temas: globalización, ambiente, pobreza y equidad. Se vio el rol de la mujer como productora y como consumidora, su derecho a la seguridad alimentaria y al acceso equitativo a los beneficios derivados de los recursos genéticos. Se analizó la importancia de empoderar a las mujeres pobres para que participen en el proceso de desarrollo humano sostenible, la necesidad de establecer políticas de equidad de género en el sector ambiental y la obligación de asegurar los derechos de las mujeres al uso sostenible de los recursos naturales.

$\begin{array}{cc}\text { 28 de febrero a } 11 & \text { Conferencia } \\ \text { y 22 de } & \text { Beijing }+\mathbf{1 0} . \\ \text { marzo 2005 } & \text { ONU }\end{array}$

Nueva York

EEUU

\begin{abstract}
Consta de 20 puntos que reafirman lo establecido en Beijing; destaca los progresos que se han hecho para lograr la igualdad entre los géneros, así como los desafíos y obstáculos que aún se oponen a su aplicación. Se subraya que la aplicación de la declaración es esencial para el logro de los objetivos de desarrollo internacionalmente convenidos (Declaración del Milenio y Declaración de Beijing). Se insta a la ONU, a las organizaciones internacionales, regionales, a todos los sectores de la sociedad civil, ONGs y a todas las mujeres y hombres a comprometerse e intensificar sus contribuciones con miras a la aplicación de la Declaración y Plataforma de Acción de Beijing.
\end{abstract}


TABLA 2 Leyes, planes, artículos y convenios interinstitucionales que promueven la equidad de género en México

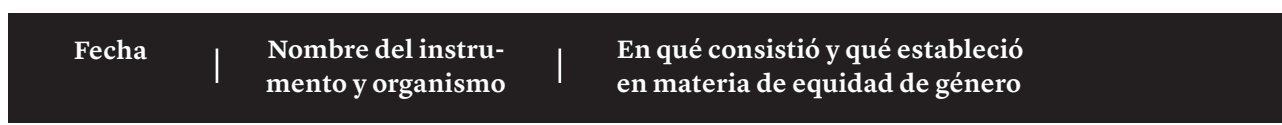
05-02-1917 y su última reforma 29-07-2010.

\section{Publicada en el diario oficial de la federación el \\ Constitución Política
de los Estados Unidos \\ Constitución Politica
de los Estados Unidos Mexicanos Gobierno de México} publicada el

Es la ley más importante que tiene México; expresa cómo deben comportarse los habitantes en el país y cuáles son sus derechos. Establece la importancia de vivir juntos y encontrar soluciones a los problemas y situaciones que se presentan, así como la manera en que debe funcionar el gobierno. En su artículo 1 establece que: "en los Estados Unidos Mexicanos todo individuo gozará de las garantías que otorga esta constitución..., queda prohibida toda discriminación motivada por origen étnico, el género, la edad, las discapacidades, la condición social, las condiciones de salud, la religión, las opiniones, las preferencias, el estado civil o cualquier otra que atente contra la dignidad humana y tenga por objeto anular o menoscabar los derechos y libertades de las personas".

$\mathrm{El}$ artículo 4 indica que: "el varón y la mujer son iguales ante la ley".

$\begin{array}{cc}27 \text { de julio de } & \text { Ley General para } \\ 2006 & \begin{array}{c}\text { la igualdad entre } \\ \text { mujeres y hombres. }\end{array}\end{array}$

1 de febrero de Ley General de 2007

Acceso de las Mujeres
a una Vida Libre de
Violencia.

Regula y garantiza la igualdad entre mujeres y hombres; propone lineamientos y mecanismos institucionales que deben orientar a la nación hacia el cumplimiento de la igualdad sustantiva en los ámbitos públicos y privados, promoviendo el empoderamiento de las mujeres. Los principios gestores de la ley son igualdad, no discriminación, equidad y todos aquellos contenidos en la Constitución Política. Establece que las autoridades e instituciones a nivel Federal, Estatal y Municipal deberán promover la igualdad entre mujeres y hombres, así como desarrollar políticas en cada estructura organizativa del gobierno. Se detallan disposiciones sobre la igualdad en la vida económica, política, civil, así como la eliminación de estereotipos en función del sexo.

Establece la coordinación entre la Federación, las entidades federativas y los municipios para prevenir, sancionar y erradicar la violencia contra las mujeres; así como los principios y modalidades para garantizar su acceso a una vida libre de violencia que favorezca su desarrollo y bienestar conforme a los principios de igualdad y no discriminación. Las disposiciones de esta ley son de orden público, interés social y de observancia general en la República Mexicana.

$\begin{array}{cc}\text { Publicado } & \text { Plan Nacional de } \\ \text { en el diario } & \text { Desarrollo } \\ \text { oficial de la } & \mathbf{2 0 1 3 - 2 0 1 8}\end{array}$

federación el

Considera que la democracia participativa es tarea de todos y es una fuente para lograr el desarrollo nacional. Al Estado le corresponde la rectoría del desarrollo nacional para garantizar que éste sea integral y sustentable, para fortalecer la soberanía de la nación, su régimen democrático y para que mediante el fomento del crecimiento económico y el empleo, mejore la equidad social y el bienestar de las familias mexicanas. Establece como metas nacionales la paz, inclusión, educación de calidad, la prosperidad y la responsabilidad global.

Presenta estrategias transversales para democratizar la productividad, para alcanzar un gobierno cercano, moderno y 
para tener una perspectiva de género en todos los programas de la Administración Pública Federal. La igualdad de oportunidades es considerada como fundamental si se desea impulsar al país. Es el primer Plan Nacional de Desarrollo que incorpora la perspectiva de género como principio esencial ya que contempla la necesidad de realizar acciones especiales orientadas a garantizar los derechos de mujeres para evitar que las diferencias de género sean causa de desigualdad, exclusión o discriminación.

\section{Decreto 20 del Ley del Instituto} 17-12-2003. Estatal de las Mujeres de Nuevo León.
El instituto fue creado con el objeto de promover y fomentar las condiciones que posibiliten la no discriminación, la equidad, la igualdad de oportunidades, de trato entre los géneros, de la toma de decisiones y de los beneficios del desarrollo; el ejercicio pleno de todos los derechos de las mujeres y su participación equitativa en la vida política, económica y social del Estado. 